\title{
Transformation and sorption of illicit drug biomarkers in sewer biofilms
}

Ramin, Pedram; Brock, Andreas Libonati; Causanilles Llanes, Ana; Valverde Pérez, Borja; Emke, Erik; de Voogt, Pim; Polesel, Fabio; Plósz, Benedek G.

\section{Published in:}

Environmental Science and Technology

Link to article, DOI:

10.1021/acs.est.6b06277

Publication date:

2017

Document Version

Peer reviewed version

Link back to DTU Orbit

Citation (APA):

Ramin, P., Brock, A. L., Causanilles Llanes, A., Valverde Pérez, B., Emke, E., de Voogt, P., Polesel, F., \& Plósz, B. G. (2017). Transformation and sorption of illicit drug biomarkers in sewer biofilms. Environmental Science and Technology, 51(18), 10572-10584. https://doi.org/10.1021/acs.est.6b06277

\section{General rights}

Copyright and moral rights for the publications made accessible in the public portal are retained by the authors and/or other copyright owners and it is a condition of accessing publications that users recognise and abide by the legal requirements associated with these rights.

- Users may download and print one copy of any publication from the public portal for the purpose of private study or research.

- You may not further distribute the material or use it for any profit-making activity or commercial gain

- You may freely distribute the URL identifying the publication in the public portal 


\section{Article}

Subscriber access provided by DTU Library

\section{Transformation and sorption of illicit drug biomarkers in sewer biofilms}

Pedram Ramin, Andreas Libonati Brock, Ana Causanilles, Borja Valverde

Pérez, Erik Emke, Pim de Voogt, Fabio Polesel, and Benedek Gy Plosz

Environ. Sci. Technol., Just Accepted Manuscript • DOI: 10.1021/acs.est.6b06277 • Publication Date (Web): 04 Jul 2017

Downloaded from http://pubs.acs.org on August 25, 2017

\section{Just Accepted}

"Just Accepted" manuscripts have been peer-reviewed and accepted for publication. They are posted online prior to technical editing, formatting for publication and author proofing. The American Chemical Society provides "Just Accepted" as a free service to the research community to expedite the dissemination of scientific material as soon as possible after acceptance. "Just Accepted" manuscripts appear in full in PDF format accompanied by an HTML abstract. "Just Accepted" manuscripts have been fully peer reviewed, but should not be considered the official version of record. They are accessible to all readers and citable by the Digital Object Identifier (DOI®). "Just Accepted" is an optional service offered to authors. Therefore, the "Just Accepted" Web site may not include all articles that will be published in the journal. After a manuscript is technically edited and formatted, it will be removed from the "Just Accepted" Web site and published as an ASAP article. Note that technical editing may introduce minor changes to the manuscript text and/or graphics which could affect content, and all legal disclaimers and ethical guidelines that apply to the journal pertain. ACS cannot be held responsible for errors or consequences arising from the use of information contained in these "Just Accepted" manuscripts. 
1 Transformation and sorption of illicit drug biomarkers in 2 sewer biofilms

3 Pedram Ramin ${ }^{\mathrm{a}, \mathrm{b}^{*}}$, Andreas Libonati Brock ${ }^{\mathrm{a}}$, Ana Causanilles ${ }^{\mathrm{c}}$, Borja 4 Valverde-Pérez ${ }^{\mathrm{a}}$, Erik Emke ${ }^{\mathrm{c}}$, Pim de Voogt ${ }^{\mathrm{c}, \mathrm{d}}$, Fabio Polesel ${ }^{\mathrm{a}}$, Benedek Gy. 5 Plósz ${ }^{\text {a,e,* }}$

6 a Department of Environmental Engineering, Technical University of Den7 mark (DTU), Bygningstorvet, Bygning 115, 2800 Kgs. Lyngby, Denmark

$8{ }^{b}$ Process and Systems Engineering Center (PROSYS), Department of Chemi9 cal and Biochemical Engineering, Technical University of Denmark, Building 10 229, 2800 Kgs. Lyngby, Denmark

$11{ }^{\mathrm{c}}$ KWR Watercycle Research Institute, P.O. Box 1072, 3430 BB Nieuwegein, 12 The Netherlands`1

13 Institute for Biodiversity and Ecosystem Dynamics, University of Amster14 dam, P.O. Box 94248, 1090 GE Amsterdam, The Netherlands

$15{ }^{\mathrm{e}}$ Department of Chemical Engineering, University of Bath, Claverton Down, 16 Bath BA2 7AY,UK

18 *Corresponding authors: pear@kt.dtu.dk; b.g.plosz@,bath.ac.uk

21 In-sewer transformation of drug biomarkers (excreted parent drugs and me22 tabolites) can be influenced by the presence of biomass in suspended form as 23 well as attached to sewer walls (biofilms). Biofilms are likely the most abun24 dant and biologically active biomass fraction in sewers. In this study, 16 drug 25 biomarkers were selected, including the major human metabolites of 26 mephedrone, methadone, cocaine, heroin, codeine and tetrahydrocannabinol 27 (THC). Transformation and sorption of these substances were assessed in tar28 geted batch experiments using laboratory-scale biofilm reactors operated un29 der aerobic and anaerobic conditions. A one-dimensional model was devel30 oped to simulate diffusive transport, abiotic and biotic transformation and 31 partitioning of drug biomarkers. Model calibration to experimental results 32 allowed estimating transformation rate constants in sewer biofilms, which 33 were compared to those obtained using in-sewer suspended biomass. 
34 Our results suggest that sewer biofilms can enhance the transformation of 35 most compounds. Through scenario simulations, we demonstrated that the 36 estimation of transformation rate constants in biofilm can be significantly 37 biased if the boundary layer thickness is not accurately estimated. This study 38 complements our previous investigation on the transformation and sorption of 39 drug biomarkers in the presence of only suspended biomass in untreated sew40 age. A better understanding of the role of sewer biofilms-also relative to the 41 in-sewer suspended solids-and improved prediction of associated fate pro42 cesses can lead to more accurate estimation of daily drug consumption in ur43 ban areas in wastewater-based epidemiological assessments.

\section{Introduction}

45 Wastewater-based epidemiology (WBE) has emerged as a new paradigm to 46 monitor trends of community-wide drug use based on chemical analysis of 47 urinary drug biomarkers in raw sewage, typically in the influent of 48 wastewater treatment plants (WWTPs). ${ }^{1,2}$ Transport in upstream sewer pipe49 lines is known to influence the quality of untreated wastewater ${ }^{3}$, hence relia50 ble estimations of drug use based on observations in WWTP influents re51 quire consideration of in-sewer transformations and sorption of biomarkers. 52 A recent investigation ${ }^{4}$ in a full-scale pressurized sewer pipeline revealed 53 significant elimination or formation of pharmaceuticals (e.g. bezafibrate and 54 sulfamethoxazole, respectively).

55 The uncertainty introduced by neglecting in-sewer processes is often ignored ${ }^{5}$ 56 among other sources of uncertainty in WBE studies. ${ }^{6}$ The in-sample stability 57 of drug biomarkers has been widely assessed ${ }^{7-10}$, providing an indication of 58 biotransformation in raw wastewater. These studies prominently addressed 59 the reliability of analysis after sample collection, focusing e.g. on biomarker 60 stability during composite sample collections, rather than refining back61 calculation schemes by accounting for in-sewer transformations. However, 62 due to differences in operation and design of sewer systems, in-sewer stabil63 ity of drugs of abuse is not only compound-specific but also highly dependent 64 upon the catchment layout (e.g., size ${ }^{11}$ ) and the hydraulic conditions in the 65 pipelines.

66 Moreover, in-sewer fate processes are not limited to biotransformation in the 67 bulk phase and biofilms/sediments, but also include abiotic processes and 68 partitioning of drug biomarkers to suspended and attached solids. Drug bi69 omarkers can be in-sewer transformation product of other human metabolites 
and hence their concentration can be significantly influenced. When considering these challenges, chemical stability in terms of percentage removal efficiency or correction factors (lumped factors that include excretion ratio, insewer transformation etc.) cannot be a reliable source of information for the estimation of drug load at the point of excretion.

75 Recently, transformation and sorption of several drug biomarkers in raw wastewater in the presence of suspended biomass have been assessed using targeted experiments and mechanistic modelling. ${ }^{12}$ This previous study elucidated the role of only one of the possible actors of in-sewer biochemical processes, as biomass in sewer systems is present also in attached form. However, limited evidence exists on the role of sewer biofilms. To date, only a few studies ${ }^{13,14}$ assessed removal kinetics in sewer biofilms, showing enhanced relative removal efficiency of selected drug biomarkers (cocaine and 6-monoacetyl-morphine) as compared to raw wastewater. Nevertheless, a number of previously uninvestigated factors are likely to influence (the estimation of) biofilm-mediated transformation rates, namely (i) sorption onto biofilm ${ }^{15}$, similarly to suspended solids in untreated wastewater ${ }^{12}$; (ii) concurrent trans87 formation and formation from other biomarkers ${ }^{8,12,16,17}$; (iii) abiotic degrada88 tion $^{5,12}$; (iv) prevailing redox conditions (aerobic and anaerobic); and (v) dif89 fusive transport through boundary layer and in biofilm ${ }^{15,18}$. While being typically neglected in biotransformation studies with biofilms, The impact of (v) may be substantial considering the structure and the thickness of sewer bio92 films and the reduced diffusivity of large organic molecules. ${ }^{19-21}$ This is es93 pecially important in pressurized sewers, where sewer biofilms are abundant 94 in completely filled pipes. ${ }^{3,22}$

95 In this study, we sought to improve the existing understanding of the fate of 96 drug biomarkers in the presence of sewer biofilms by means of an experi97 mental and model-based assessment. This study was meant to complement 98 our previous investigation ${ }^{12}$ on the fate of drug biomarkers in untreated sew99 age, in the presence of only suspended biomass. The objectives of our inves100 tigation were thus: (i) to assess the transformation and sorption of 16 drug 101 biomarkers in sewer biofilms under aerobic and anaerobic conditions (using 102 laboratory-scale rotating biofilm reactors); (ii) to model the fate of selected 103 drug biomarkers in the biofilm by explicitly describing diffusive transport 104 and reaction kinetics; (iii) to estimate biofilm-mediated biotransformation 105 kinetics for the selected biomarkers, and to compare them with transfor106 mation kinetics by suspended biomass in untreated wastewater. 


\section{Materials and methods}

108 Selection of trace organic biomarkers. Six illicit drugs were selected based

109 on their high consumption levels according to a recent European report. ${ }^{23}$ The

110 target list was completed with 10 human metabolites and included: (i)

111 mephedrone (MEPH); (ii) methadone (METD) and its metabolite 2-

112 ethylidene-1,5-dimethyl-3,3-diphenylpyrrolidine (EDDP); (iii) cocaine

113 (COC) and its metabolites benzoylecgonine (BE), ecgonine methyl ester

114 (EME), and cocaethylene (CE); (iv) heroin (HER) and its metabolites 6-

115 monoacetylmorphine (6-MAM), morphine (MOR), and morphine-3- $\beta$-D-

116 glucuronide (MORG); codeine (COE) and its metabolite norcodeine (NCOE);

117 (v) tetrahydrocannabinol (THC) and its metabolites 11-hydroxy- $\triangle 9$-THC

118 (THCOH), and 11-nor-9-carboxy- $\Delta$ 9-THC (THCCOOH). COE and NCOE

119 were also considered in the same group as MOR, since COE can potentially

120 transform to MOR and NCOE during human metabolism. ${ }^{24}$ Analytical Stand-

121 ards (IS) and isotopically labeled internal standard (ILIS) analogues from

122 Sigma Aldrich (Brøndby, Denmark) were dissolved in methanol or acetoni-

123 trile at concentrations of $0.1 \mathrm{mg} \mathrm{mL}^{-1}$ and $1 \mathrm{mg} \mathrm{mL}^{-1}$, respectively. Poor data

124 quality prevented us from assessing the transformation of methamphetamine

125 and amphetamine, which are widely used in Europe. ${ }^{23}$

126 Experimental set-up with continuous-flow operation. Two annular rotating

127 biofilm reactors, made of poly(methyl methacrylate) (Plexiglas), operated

128 either under aerobic or anaerobic conditions with operating volume of 0.961

129 L, were used to simulate in-sewer conditions by controlling, e.g., shear condi-

130 tions on biofilm. The reactors consisted of an inner rotating drum (diame-

131 ter $=9.0 \mathrm{~cm}$ ) and an outer stationary cylinder (diameter $=11.4 \mathrm{~cm})$, supporting

132 the growth of attached biomass. This type of reactor provided for high sur-

133 face area to volume ratio $\left(175 \mathrm{~m}^{2} \mathrm{~m}^{-3}\right)$ that could be advantageous for biofilm

134 growth. Each reactor was equipped with four removable slides, allowing for

135 inspection of biofilm during reactor operation.

136 In order to establish stable aerobic and anaerobic biofilms, the two reactors were

137 operated under continuous-flow conditions for more than 7 months while being

138 kept in the dark. The rotation speed of the reactors was set to $20 \mathrm{rpm}$. The wall

139 shear stress was calculated according to equations provided by Rochex et al. ${ }^{25}$ as

$1400.05 \mathrm{~Pa}$ which is in the lower range of typical wall shear stress in the sewers, 141 measured up to $3 \mathrm{~Pa}$ in a gravity sewer. ${ }^{26}$ Low shear stress was chosen in order to

142 decrease biofilm sloughing and therefore enhance biofilm thickness. The reac-

143 tors were continuously fed $\left(4 \mathrm{~L} \mathrm{~d}^{-1}\right.$, hydraulic residence time of approximate- 
144 ly $0.25 \mathrm{~d}^{-1}$ ) with pre-clarified wastewater from external cooled containers ( $\mathrm{T}$ $145 \leq 4^{\circ} \mathrm{C}$ ) that were sparged with dry compressed atmospheric air (aerobic reac146 tor) or nitrogen (anaerobic reactor). The experiments were designed and per-

147 formed to mimic completely aerobic and anaerobic redox conditions as closely as

148 possible. The external tanks were filled with pre-clarified wastewater collected

149 from Mølleåværket WWTP (Lundtofte, Denmark) semi-weekly. The wastewater

150 had following characteristics: soluble organic carbon, expressed as chemical ox151 ygen demand $(\mathrm{COD})=40-130 \mathrm{~g} \mathrm{~m}^{-3}$, total COD $\left(120-\mathrm{g} \mathrm{m}^{-3}\right)$, biological oxygen

152 demand $(\mathrm{BOD})=90-200 \mathrm{~g} \mathrm{~m}^{-3}$, nitrate $<1 \mathrm{gN} \mathrm{m}^{-3}$, total nitrogen $(\mathrm{TN})=20-50$

$153 \mathrm{gN} \mathrm{m}^{-3}$, sulfate $=12-55 \mathrm{gS} \mathrm{m}^{-3}$.

154

155 Laboratory-scale batch experiments. Following long-term continuous-flow 156 operation, two sets of batch experiments were performed: (i) biotransfor-

157 mation experiments with intact biofilm in rotating reactors (BT); and (ii)

158 sorption experiments with re-suspended biofilm (SO). All experiments were

159 started $(\mathrm{t}=0)$ three minutes after spiking of biomarker standard solutions to

160 ensure mixing of spiked biomarkers in solution. Figure 1 illustrates the reac-

161 tor configuration and operation during BT Experiments. During the entire

162 operation, the biofilm reactors were kept full and intermittent wetting was

163 avoided to prevent reduction of the overall activity of the biofilm. A detailed

164 description of each set of batch experiments is provided below. Description

165 of all batch experiments is also presented in SI Table S2.

166 Biotransformation experiments (BT). Each rotating biofilm reactor was con-

167 nected to an external container with a recirculating flow of $4 \mathrm{~L} \mathrm{~h}^{-1}$. This con-

168 figuration allowed for sample collection from the external container without

169 changing the operating volume of the biofilm reactors. Two procedures were

170 considered. The first procedure (BT-P1) was conducted by spiking a mixture

171 containing all IS to obtain an initial $(\mathrm{t}=0)$ concentration of $10 \mu \mathrm{g} \mathrm{L}^{-1}$. Follow-

172 ing sample withdrawal during experiments, samples were immediately spiked

173 with a mixture containing ILIS. The IS solution mixture contained the main

174 target compounds and ILIS were used to evaluate the analytical procedure.

175 The second procedure (BT-P2) was conducted by spiking ILIS at initial $(\mathrm{t}=0)$

176 concentration of $2 \mu \mathrm{g} \mathrm{L}^{-1}$. In this second case only ILIS were spiked and con-

177 sidered the target compounds, including only MEPH-d3, METD-d3, EDDP-

$178 \mathrm{~d} 3$, COC-d3, BE-d3, EME-d3, CE-d3, HER-d9 and 6MAM-d3. This proce-

179 dure allowed for the improved determination of illicit drug analytes without

180 interference of background concentrations (SI, Figure S3). ${ }^{13}$ 
181 The duration of the experiments was two days, during which 9 samples for 182 BT-P1 and 12 samples for BT-P2 experiments were collected (around 260 $183 \mathrm{~mL}$ sample volume, see SI, Figure S2). During BT-P1 experiments, additional 184 samples were collected (i) before biomarker spiking, to measure the back185 ground concentrations; and (ii) during experiments, to monitor the biological 186 activity of the biofilms via measurements of chemical oxygen demand 187 (COD), sulfate $\left(\mathrm{SO}_{4}-\mathrm{S}\right)$, ammonium $\left(\mathrm{NH}_{4}-\mathrm{N}\right)$ and nitrate $\left(\mathrm{NO}_{3}-\mathrm{N}\right)$.

188 BT-P1 and BT-P2 experiments were conducted after continuous-flow opera189 tion of biofilm reactors for 14 and 7 months, respectively assuming biofilm 190 reached maximum thickness. In this study, results of BT-P1 and BT-P2 ex191 periments were used for model identification/calibration (i.e., estimation of 192 kinetic parameters and identification of transformation pathways) and for 193 model evaluation, respectively. For BT-P1 experiments (aerobic: $194 \mathrm{pH}=8.7 \pm 0.1, \mathrm{~T}=17 \pm 0.3{ }^{\circ} \mathrm{C}$; anaerobic: $\mathrm{pH}=9.2 \pm 0.4, \mathrm{~T}=17.8 \pm 0.5^{\circ} \mathrm{C}$ ), and $\mathrm{BT}$ 195 P2 experiments (aerobic: $\mathrm{pH}=8.8 \pm 0.06, \mathrm{~T}=17.6 \pm 0.2{ }^{\circ} \mathrm{C}$; anaerobic: $\left.196 \mathrm{pH}=8.7 \pm 0.2, \mathrm{~T}=17.5 \pm 0.4^{\circ} \mathrm{C}\right)$, wastewater was collected from Mølleåværket 197 WWTP (Lundtofte, Denmark). Collected pre-clarified wastewater was centri198 fuged (20 min, $4700 \mathrm{rpm}$ ) and vacuum filtered (Advantec MFS, Inc., GA-55 199 grade) for removal of suspended solids.

200 Sorption experiments (SO). Sorption experiments (SO) were performed with 201 suspended aerobic biofilms (SO1) and suspended anaerobic biofilms (SO2). 202 The experiments were conducted after 14 months of continuous-flow opera203 tion of the biofilm reactors. Tap water was circulated through the biofilm re204 actors for $17 \mathrm{~h}$ to wash-off already sorbed compounds in the biofilm. Two 205 slides were removed from each reactor and intact biofilm was suspended in 2 206 L tap water for $4 \mathrm{~h}$ for further desorption. After centrifugation (30 min, 4700 $207 \mathrm{rpm}$ ), the separated solids were mixed with $4 \mathrm{~L}$ vacuum filtered (Advantec 208 MFS, Inc., GA-55 grade, pore size $6 \mu \mathrm{m}$ ) wastewater effluent (Mølleåværket 209 WWTP, Lundtofte, Denmark). To inactivate biomass during experiment, so210 dium azide $(0.05 \% \mathrm{v} / \mathrm{v})$ was added to the mixture. The experiments were 211 conducted for $4 \mathrm{~h}$ after spiking standard mixture and in total six samples (260 $212 \mathrm{~mL})$ were withdrawn. During SO1 experiment $\left(\mathrm{pH}=7.9 \pm 0.1, \mathrm{~T}=15.4 \pm 0.2^{\circ} \mathrm{C}\right)$ 213 and $\mathrm{SO} 2$ experiment $\left(\mathrm{pH}=7.9 \pm 0.1, \mathrm{~T}=15.3 \pm 0.1^{\circ} \mathrm{C}\right)$, the reactors were sparged 214 with dried compressed air and nitrogen, respectively.

215 Biofilm characterization. The biofilm thickness (aerobic: $0.75 \mathrm{~mm}$; anaero216 bic: $1.02 \mathrm{~mm}$ ) was calculated by measuring biofilm volume and considering 217 the reactor surface area of $1679 \mathrm{~cm}^{2}$. The biofilm volume was measured by 
218 filling the rotating reactors with tap water without and with biofilm inside the 219 reactors. The difference between the volume of the empty reactor without 220 biofilm $\left(961 \mathrm{~cm}^{3}\right)$ and the free volume of the reactors with biofilm (aerobic 221 reactor, $836 \mathrm{~cm}^{3}$; anaerobic reactor, $790 \mathrm{~cm}^{3}$ ) was considered as the wet bio222 film volume. The solids content of the biofilm was measured by re223 suspending the biofilm on two removable slides into tap water, and subse224 quently measuring total suspended solids (TSS) and volatile suspended solid 225 (VSS) of the mixture. The total dried mass per biofilm volume in the reactors, 226 defined as biofilm density, was then calculated (aerobic reactor, $55 \mathrm{gTSS} \mathrm{L}^{-1}$, $22722 \mathrm{gVSS}^{-1} \mathrm{~L}^{-1}$; anaerobic reactor, $\left.83 \mathrm{gTSS} \mathrm{L}^{-1}, 38 \mathrm{gVSS}^{-1} \mathrm{~L}^{-1}\right)$.

228 Sample preparation and chemical analyses. Total suspended solids (TSS) 229 were measured using gravimetric analysis after filtration $(0.6 \mu \mathrm{m}$ glass fiber 230 filter, Advantec, USA). ${ }^{27}$ Total and soluble COD, nitrate, ammonium and sul231 fate were measured using colorimetric methods (Hach Lange and Merck, 232 Germany). For dissolved components, the analyses were carried out after 233 sample filtration $(0.45 \mu \mathrm{m}$ cellulose acetate filters, Sartorius, Germany) and 234 storage at $-20^{\circ} \mathrm{C}$.

235 For the analysis of drug biomarkers (one sample at each sampling time), a 236 description of sample preparation and chemical analysis by liquid chromatog237 raphy coupled to high resolution mass spectrometry (HPLC-LTQ-Orbitrap) 238 can be found elsewhere. ${ }^{12,28}$ Briefly, samples were collected and immediately 239 frozen until analysis. For samples from SO experiments samples were first 240 filtered (0.6 $\mu \mathrm{m}$ glass fiber filter, Advantec, USA) to reduce the contact time 241 between solids and liquid phase. Later, samples were thawed and homoge242 nized, and $100 \mathrm{~mL}$ aliquots were extracted by solid phase extraction with Oa243 sis HLB cartridges ( $150 \mathrm{mg}, 6 \mathrm{cc}$, Waters, Denmark). Extracts were reconsti244 tuted in water:methanol (90:10, v/v) and $20 \mu \mathrm{L}$ were injected into the HPLC245 LTQ-Orbitrap. Separation of the target compounds was achieved in an 246 XBridge C18 column $(150 \mathrm{~mm} \times 2.1 \mathrm{~mm}$, I.D., particle size $3.5 \mu \mathrm{m}$; Waters $)$ 247 with a MiliQ and $\mathrm{MeOH}$ optimized gradient (each with $0.05 \%$ formic acid). 248 Full scan accurate mass data were acquired in positive electrospray ionization 249 mode over a m/z range of 50-600 Da at a resolution of 30000 full width at 250 half maximum. For confirmation purposes, information about the fragmenta251 tion spectra of the target compounds was obtained by product-ion scan mode 252 of the target masses inclusion list, in the same analysis. All data were ac253 quired and processed using Xcalibur version 2.1 software. 
254 Modeling framework. The mathematical description of fate processes was

255 formulated by accounting for temporal and spatial variation of target analyte 256 concentrations in biofilms. Due to mass transfer limitation from the bulk 257 phase to the biofilm and within the biofilm, concentration gradients can occur 258 in the biofilm reactors. For the specific case of batch experiments, it was as259 sumed that the biofilm is at steady state and as a homogeneous biomass. The 260 volume inside the biofilm reactors was constant, whereas in the external tank 261 the volume decreased due to withdrawal of samples. Thus, the contact time 262 between the dissolved compounds in liquid phase and biofilm increased, 263 which could potentially enhance biomarker transformation. Consequently, 264 residence time dynamics were also included in the model by accounting for 265 volume changes in the external tank (SI Figure S2). As illustrated in Figure 1, 266 the experimental system consists of three compartments: (i) the bulk liquid in 267 the rotating reactor, (ii) the biofilm in the rotating reactor and (iii) the exter268 nal tank (continuously stirred tank reactor) connected to the biofilm reactor 269 via a peristaltic pump. The differential equations describing mass balances in 270 each compartment can be formulated as follows (all model parameters and 271 state variables are listed in Table 1):

272 i) In the biofilm reactor bulk phase:

$273 \quad \frac{d V_{R} C_{R, i}}{d t}=Q_{\text {in }, R} C_{\text {in }, R, i}-Q_{\text {out }, R} C_{R, i}-j_{b} A_{b}+r_{R, i} V_{R}$

274 ii) In the biofilm:

$275 \quad \frac{\partial V_{b} C_{b, i}}{\partial t}=A_{b} D \frac{\partial^{2} C_{b, i}}{\partial z^{2}} \Delta z+r_{b, i} V_{b}$

276 iii) In the external tank:

$277 \quad \frac{d V_{T} C_{T, i}}{d t}=Q_{i n, T} C_{i n, T, i}-Q_{o u t, T} C_{T, i}+r_{T, i} V_{T}$

278 In these formulations, $C\left(\mathrm{~g} \mathrm{~m}^{-3}\right)$ denotes the concentration as state variable 279 and the subscripts $R, b$ and $T$ indicate bulk phase of the rotating reactor, the 280 biofilm, and the external tank, respectively. The volume, which is constant 281 for the reactor bulk phase $V_{R}\left(\mathrm{~m}^{-3}\right)$ and the biofilm $V_{b}\left(\mathrm{~m}^{-3}\right)$, changes as a 282 function of time inside the external tank, $V_{T}\left(\mathrm{~m}^{-3}\right)$, as previously explained.

283 Transport processes. The flux of compounds between bulk phase and the bio284 film, $j_{b}\left(\mathrm{~g} \mathrm{~m}^{-2} \mathrm{~d}^{-1}\right)$, is expressed using film theory at the mass transfer bounda285 ry layer ${ }^{29}$. The flux of compounds across the boundary layer can be defined 286 as: 
$287 j_{b}=k_{b}\left(C_{R}-C_{L}\right)=\frac{D}{L_{b}}\left(C_{R}-C_{L}\right)$

288 Where $k_{b}\left(\mathrm{~m} \mathrm{~d}^{-1}\right)$ is the liquid-biofilm mass transfer coefficient, $D\left(\mathrm{~m}^{2} \mathrm{~d}^{-1}\right)$ is 289 the diffusion coefficient of the dissolved compounds into the biofilm, $L_{b}(\mathrm{~m})$ 290 is the biofilm thickness, and $C_{L}$ is the concentration at the biofilm-liquid in291 terface (top layer). It was assumed that no reactions occur in the boundary 292 layer. The diffusion coefficients of target biomarkers in water, $D_{w}\left(\mathrm{~m}^{2} \mathrm{~d}^{-1}\right)$ 293 were calculated based on the revised Othmer-Thakar ${ }^{30}$ equation suggested by 294 Hayduk and Laudie ${ }^{31}$ :

$295 D_{w}=\frac{13.26\left(10^{-5}\right)}{\mu_{w}{ }^{1.4} V_{1}^{0.589}}$,

296 where $\mu_{w}\left(\mathrm{~kg} \mathrm{~m}^{-1} \mathrm{~s}^{-1}\right)$ denotes the dynamic viscosity of water and $V_{l}\left(\mathrm{~cm}^{3} \mathrm{~g}\right.$ $\left.297 \mathrm{~mole}^{-1}\right)$ is the molar volume of the substance. Diffusion coefficients $\left(D_{W}\right)$ cal298 culated using eq. 5 are reported in Table S1. Diffusion coefficients inside the 299 biofilm were assumed to be reduced as compared to bulk water phase. Re300 duced effective diffusivity results from limitation due to increased path 301 length in biofilm pores as compared to free aqueous media. Consequently, a 302 dimensionless effective diffusivity factor, $f$, was considered:

303 $D=f D_{w}$

304 The value of $f$ was approximated by considering the density of the biofilm as 305 VSS $\left(\mathrm{gVSS} \mathrm{L}^{-1}\right)$, based on the regression presented by Guimerà et al. ${ }^{32}$ The 306 boundary layer thickness, $L_{b}$, was estimated using dimensionless numbers, $307 \quad 33,34$ namely Sherwood number $(S h)$, Schmidt number $(S c)$, Taylor number $308(T a)$ and Reynolds number (Re), (see SI, eqs. S1 to S4).

309 Reaction processes. Reaction kinetics in the bulk phase of the biofilm reactor 310 includes abiotic processes and biotransformation due to the presence of sus311 pended biomass. The amount of suspended solids was the residuals of solids 312 that remained in filtered wastewater (measured at $\mathrm{t}=0$ ) and amount of de313 tached biomass assumed to be negligible. These processes were formulated 314 according to the Activated Sludge Model for Xenobiotics (ASM-X) frame315 work. ${ }^{12,16}$ The reaction rate for transformation of compound $i$ and its for316 mation from compound $j$ can be formulated as:

$317 r_{R, i}=-k_{a b i o} C_{R, i}+k_{a b i o} C_{R, j} \frac{M_{i}}{M_{j}}-\frac{k_{b i o} X_{S S}}{\left(1+K_{d, i} X_{S S}\right)} C_{R, i}+\frac{k_{b i o} X_{S S}}{\left(1+K_{d, j} X_{S S}\right)} C_{R, j} \frac{M_{i}}{M_{j}}$ 318 (eq. 7) 
319 Where $k_{\text {abio }}\left(\mathrm{d}^{-1}\right)$ is the abiotic transformation rate, $k_{\text {bio }}\left(\mathrm{L} \mathrm{gTSS}^{-1} \mathrm{~d}^{-1}\right)$ is the

320 TSS-normalized biotransformation rate constant for the suspended solids, $K_{d}$

$321\left(\mathrm{~L} \mathrm{gTSS}^{-1}\right)$ is the partitioning coefficient to suspended solids $X_{S S}\left(\mathrm{~g} \mathrm{~L}^{-1}\right)$, and

$322 M$ is the molecular weight. Equilibrium processes were assumed for sorption

323 and desorption onto suspended solids.

324 Inside the biofilm, in addition to abiotic processes, transformation and for-

325 mation processes resulted from the microbial activity of the attached biomass.

326 The associated kinetic equations were expressed as:

327

$r_{b, i}=-k_{a b i o} C_{R, i}+k_{a b i o} C_{R, j} \frac{M_{i}}{M_{j}}-k_{f, i} C_{b, i}+k_{f, j} C_{b, j} \frac{M_{i}}{M_{j}}$

$328 k_{f, j}=\frac{k_{b i o f, j} X_{S S}}{\left(1+K_{d f, j} X_{S S}\right)}$

329 In this formulation, biofilm-mediated transformation (subscript $f$ ) is ex-

330 pressed using pseudo-first order kinetics, where $k_{f}$ and $k_{b i o f}$ are in units of $\mathrm{d}^{-1}$ 331 and $\mathrm{L} \mathrm{gTSS}^{-1} \mathrm{~d}^{-1}$, respectively, and $K_{d f}\left(\mathrm{~L} \mathrm{gTSS}^{-1} \mathrm{~d}^{-1}\right)$ is the partitioning coef-

332 ficient in biofilms. Biofilm-mediated transformation can also be expressed by 333 surface-normalized rate constants $k^{\prime}{ }_{\text {biof }}\left(\mathrm{m}^{3} \mathrm{~m}^{-2} \mathrm{~d}^{-1}\right)$, obtained by dividing $k_{\text {biof }}$ 334 with $X_{S S} \times A_{b} / V_{b}$. The units of the reactions rates were adjusted to $\mathrm{g} \mathrm{m}^{3} \mathrm{~d}^{-1}$ ac335 cording to the units in eq. 1-3.

336 Finally, the reaction kinetics in the external tanks were assumed to be the 337 same as in the bulk aqueous phase of the biofilm reactor, with additional pro338 cesses for sorption and desorption to and from the tank wall ${ }^{12}$ :

$r_{T, i}=r_{R, i}-k_{d e s, w} k_{d, w} C_{T, i} \frac{A_{T}}{V_{T}}+k_{d e s, w} C_{T w}$

340 Where $C_{T w}\left(\mathrm{~g} \mathrm{~L}^{-1}\right)$ denotes the biomarker concentration sorbed onto reactor 341 wall, $K_{d, w}\left(\mathrm{~m}^{3} \mathrm{~m}^{-2} \mathrm{~d}^{-1}\right)$ the partitioning coefficient to reactor wall. and $k_{d e s, w}\left(\mathrm{~d}^{-}\right.$ $342^{1}$ ) is the desorption rate from the reactor wall.

343 In-sewer transformation pathways. Transformation and formation process344 es defined in eqs. 7-10 depend on the pathways identified for abiotic pro345 cesses, transformation due to presence of suspended solids and biofilm346 mediated transformations. The first two were adopted from our previous 347 study. ${ }^{12}$ Transformation pathways in biofilms were initially assumed based on 348 reported human metabolic pathways. ${ }^{7,35}$ This initial assumption was required 349 due to the absence of a priori evidence and was tested as part of the model350 ling study. Subsequently, any deviation from the initial pathways was as351 sessed by examining the mass balance over suggested transformed com- 
352 pounds and observed transformation products (according to human metabo353 lism).

354 Model parameter estimation. The values employed for $k_{a b i o}$ and $k_{b i o}$ for sus355 pended biomass in bulk phase were estimated in an another study. ${ }^{12}$ Using 356 SO1 and SO2 measurements (SI, Figure S8) the $K_{d f}$ values were estimated 357 according to Ramin et al. ${ }^{12}$ Values of $k_{f}$ were estimated using the Bayesian 358 optimization method Differential Evolution Adaptive Metropolis $359\left(\right.$ DREAM $\left._{(\mathrm{ZS})}\right){ }^{36}$ The normalized sum of squared error (SSE) was used as ob360 jective function:

$361 \quad S S E=\sum_{i=1}^{n} \sum_{j=1}^{m}\left(\frac{O_{i, j}-P_{i, j}}{O_{i, j, \max }-O_{i, j, \min }}\right)^{2}$

362 Where $n$ is the number of measurements series and $m$ is the number of the 363 data points in each series. $O$ denotes measured data, $P$ model predictions, and $364 O_{i, j, \max }$ and $O_{i, j, \text { min }}$ the maximum and minimum of measurements, respective365 ly. To adequately quantify the uncertainty associated to the $k_{f}$ estimates, the 366 uncertainty from $k_{\text {abio }}$ and $k_{\text {bio }}$ was propagated according to the identified 367 transformation pathways for abiotic processes and biotransformation in pres368 ence of suspended solids. ${ }^{37}$ Values of $k_{\text {biof }}$ were eventually estimated based on 369 eq. 9. We considered an upper boundary threshold of $10^{4} \mathrm{~d}^{-1}$ for $k_{f}$ in parame370 ter estimation. Parameter estimates beyond this threshold were considered to 371 result from model structure deficiencies (related to mass transfer).

372 Model simulation and evaluation. To simulate the transformation processes, 373 eqs. 1-3 were numerically solved following a spatial discretization of the bio374 film. Theoretically, increasing the discretization level (grid points) would 375 increase the accuracy of prediction at the expense of higher computational 376 time. For central grids (inside the biofilm), discretization was done using the 377 central difference formula. Values at the first grid (biofilm-liquid interface) 378 and the last grid points were computed via forward and backward difference, 379 respectively. This discretization scheme was adopted from the biofilm simu380 lation model developed by Vangsgaard et al. ${ }^{38}$ The resulting set of ordinary 381 differential equations was solved using the stiff ODE solver ode15s in Matlab 382 R2014a (MathWorks, US). Model parameter uncertainty was assessed using 383 the posterior probability distribution of estimates in Monte Carlo simulations 384 as explained elsewhere. ${ }^{39}$ Subsequently, the accuracy of the predictions was 385 visually evaluated comparing measurements from BT-P2 experiments, i.e. an 386 independent dataset, with model predictions. 


\section{Results and discussion}

388 Biological activity of biofilm reactors. To monitor microbial activity in aer389 obic and anaerobic biofilms, soluble COD, sulfate and ammonium (Figure 2) 390 as well as total COD and nitrate (SI, Figure S4) were monitored in the bulk 391 phase during the BT-P1 experiments (while reactors were disconnected from 392 continuous feeding). Soluble COD consisted of readily biodegradable organic 393 substrates and soluble inert fractions, including $\mathrm{MeOH}$ present in the spiking 394 solution. Utilization of $\mathrm{MeOH}$ as growth substrate was assumed to be negli395 gible as in our previous study ${ }^{12}$ we did not observe any substantial difference 396 in suspended biomass growth and oxygen uptake response upon $\mathrm{MeOH}$ addi397 tion. Due to the likely higher activity of heterotrophic biomass under aerobic 398 conditions as well as higher $\mathrm{MeOH}$ evaporation rate (dried air was sparged at 399 a higher flow rate in the external tank compared to nitrogen gas), higher re400 moval of soluble COD was observed in the aerobic reactor (88\%) compared 401 to the anaerobic one (57\%) over $2 \mathrm{~d}$. Due to the activity of sulfate reducing 402 bacteria (SRB), sulfate was significantly reduced under anaerobic conditions $403(62 \%$ over $1 \mathrm{~d})$ and remained constant during last day of experiment (Figure 404 2b). This may indicate that sulfate respiration by SRB species was limited by 405 the absence of readily biodegradable substrate during the second day of ex406 periment. Under aerobic conditions, the net formation $(+33 \%)$ of sulfate was 407 observed over $2 \mathrm{~d}$, possibly due to biochemical oxidation of hydrogen sulfide $408\left(\mathrm{H}_{2} \mathrm{~S}\right)$ back to sulfate. In the aerobic BT-P1 reactor, ammonium removal is 409 possibly dominated by assimilatory ammonia uptake. It is also reported that 410 nitrifiers are usually overgrown by heterotrophic biomass in sewer biofilms 411 (Huisman and Gujer, 2002; Jiang et al., 2009). Under anaerobic conditions, 412 ammonium removal could be due to assimilation and stripping - latter due to 413 the comparably high $\mathrm{pH}$ (9.2). 
415 Partitioning of drug biomarkers to biofilm. Two solid-liquid partitioning 416 coefficients were estimated for aerobic $\left(K_{d f, a e}\right)$ and anaerobic biofilms $\left(K_{d f, a n}\right)$ 417 using SO1 and SO2 experimental data, respectively (SI Figure S8). In addi418 tion, abiotic chemical transformation was assessed in mineral water spiked 419 with the selected biomarkers - a study carried out previously. ${ }^{12}$ These data 420 were considered to disregard the contribution of abiotic transformation during 421 sorption experiments. Estimated partitioning coefficients are reported in SI 422 Table S4. The highest sorption capacity was found for $\mathrm{THCOH}\left(K_{d f, a e}=2.81 \mathrm{~L}\right.$ $\left.423 \mathrm{gTSS}^{-1} ; K_{d f, a n}=1.68 \mathrm{~L} \mathrm{gTSS}^{-1}\right)$. The drop in THC concentration in the sorption 424 experiments ( $72 \%$ in aerobic biofilms and 58\% in anaerobic biofilm) can be 425 interpreted as a result of chemical partitioning to external tank wall, as it was 426 observed previously ${ }^{12}$, with the $K_{d f}$ values being negligible despite the high 427 hydrophobicity of this chemical $\left(\log K_{o w}=7.6\right) .{ }^{40}$ However, given the high hy428 drophobicity of THC, high sorption onto biofilm solids could not be ruled 429 out, and further experimental confirmation may be required to verify our 430 findings. Sorption of THCCOOH, EME and EDDP was only observed for 431 anaerobic biofilms $\left(K_{d f, a n}=1.06 \mathrm{~L} \mathrm{gTSS}^{-1} ; 1.59 \mathrm{~L} \mathrm{gTSS}^{-1} ; K_{d f, a n}=0.15 \mathrm{~L} \mathrm{gTSS}^{-1}\right.$ 432 respectively). Conversely, partitioning under aerobic conditions was found 433 for $\mathrm{MEPH}\left(K_{d f, a e}=0.20 \mathrm{~L}_{\mathrm{gTSS}}{ }^{-1}\right)$. For the remaining chemicals, negligible 434 sorption was observed, hence $K_{d f}$ values were set to zero. Notably, the anaer435 obic biofilm had higher thickness and density compared to the aerobic bio436 film, which may explain the selective sorption of some of the drug bi437 omarkers.

438 Transformation of drug biomarkers. Measurements from BT-P1 experi439 ments were used to calibrate developed 1-D model and to predict temporal 440 and spatial concentration profiles of drug biomarkers in the presence of sewer 441 biofilms. Biotransformation due to the presence of suspended solids was ac442 counted for by including previously estimated $k_{b i o}\left(\mathrm{~L} \mathrm{gTSS}^{-1} \mathrm{~d}^{-1}\right)^{12,37}$ (SI, Ta443 ble S3). Measured TSS concentrations in the bulk were considered constant, 444 namely, $42 \mathrm{mgTSS} \mathrm{L}^{-1}$ and $104 \mathrm{mgTSS} \mathrm{L}^{-1}$ (for BT-P1 aerobic and anaerobic, 445 respectively) $92 \mathrm{mgTSS} \mathrm{L}^{-1}$ and $80 \mathrm{mgTSS} \mathrm{L}^{-1}$ (for BT-P2 aerobic and anaer446 obic, respectively). The abiotic transformation rates $k_{a b i o}$ and partitioning co447 efficients of drug biomarkers to suspended solids, $K_{d}\left(\mathrm{~L} \mathrm{gTSS}^{-1}\right)$, were set at 448 values reported in SI, Table S3. ${ }^{12}$ Subsequently, biofilm-mediated biotrans449 formation rates $k_{f}\left(\mathrm{~d}^{-1}\right)$ and rate constants $k_{\text {biof }}\left(\mathrm{L} \mathrm{gTSS}^{-1} \mathrm{~d}^{-1}\right)$ and $k^{\prime}{ }_{b i o f}\left(\mathrm{~m}^{3} \mathrm{~m}^{-2}\right.$ $450 \mathrm{~d}^{-1}$ ) were estimated.

451 Measured and simulated concentration profiles of all targeted biomarkers, 452 obtained through model calibration and validation, are presented in Figure 3. 
453 Experimental and simulation results describe removal and formation of se454 lected drug biomarkers in the bulk phase of the biofilm reactor, where sam455 ples were collected. The simulation results obtained through model calibra456 tion are presented using the median of the estimated parameters (full and 457 dash lines) with the corresponding 95\% credibility interval (shaded uncertain458 ty band). The uncertainty boundary ranges, shown in Figure 3, were obtained 459 through the propagation of the uncertainties from abiotic and biotic transfor460 mation rates (quantified here or previously ${ }^{12}$ ) to the model outputs. The trans461 formation pathways identified in this study are presented in Figure S6-7. Pa462 rameter values estimated (reported as median \pm credibility interval) are listed 463 in Table S5 and all posterior distributions of $k_{f}$ values are given in Figure 464 S11. Experimental and modelling results are presented and discussed in detail 465 for each group of chemicals in the following paragraphs.

466 Prior to estimating values of $k_{f}$, the impact of discretization number (i.e. the 467 number of layers in which the biofilm is discretized) on the prediction accu468 racy was assessed. The case of the aerobic transformation rates for MEPH, $469 k_{f, a e, M E P H}$, and HER, $k_{f, a e, H E R}$, is discussed in detail (Figure 4, X-Z axis; Figure 470 S5). HER and MEPH were chosen because they represent compounds with 471 low and high removal rate, respectively. Discretization numbers, selected in 472 the interval of 5-100 layers, were used to estimate $k_{f}$ and using the highest 473 level used to benchmark the level of error introduced by inaccurate model 474 simulations. The difference is reported as relative percentage error, in which 475 best-fit estimates for $k_{f, a e, H E R}$ and $k_{f, a e, M E P H}$ were compared with their corre476 sponding reference values, $214.1 \mathrm{~d}^{-1}$ and $24.3 \mathrm{~d}^{-1}$, respectively. It was ob477 served that the number of discretization had a different impact on the esti478 mated $k_{f}$ of these two chemicals, and that after 80 grid points the resulting 479 error was negligible $(<1 \%)$ and independent of the discretization number. 480 This discretization number corresponds to $\Delta \mathrm{Z}=9.3 \mu \mathrm{m}$ and $\Delta \mathrm{Z}=12.8 \mu \mathrm{m}$ for 481 aerobic and anaerobic biofilms, respectively.

482 Mephedrone. MEPH removal was more pronounced in the aerobic reactor 483 (77\% versus $47 \%$ in the anaerobic reactor). Higher partitioning to aerobic 484 biofilms resulted in much higher biotransformation rate constants under aero485 bic conditions ( $k_{\text {biof, } a e, M E P H}=5.89 \mathrm{~L} \mathrm{gTSS}^{-1} \mathrm{~d}^{-1}, k_{\text {biof,an,MEPH }}=0.08 \mathrm{~L} \mathrm{gTSS}^{-1} \mathrm{~d}^{-1}$ ). 486 The comparably high sorption of MEPH in aerobic biofilms $\left(K_{d f, a e}=0.2 \mathrm{~L}\right.$ $487 \mathrm{gTSS}^{-1}$ ) makes this compound less bioavailable for microbial transformation. 488 This impact is also reflected in eq. 9, in which $k_{\text {biof }}$ is in the numerator and $K_{d f}$ 489 is in denominator. Moreover, the higher aerobic $k_{\text {biof }}$ obtained in this study 490 agrees well with those reported previously ${ }^{12}\left(k_{b i o, a e, M E P H}=1.86 \mathrm{~L} \mathrm{gTSS}^{-1} \mathrm{~d}^{-1}\right.$, 
$491 k_{\text {bio,an,MEPH }}=0 \mathrm{~L} \mathrm{gTSS}^{-1} \mathrm{~d}^{-1}$ ). The model could adequately simulate BT-P2 da492 taset under both redox conditions, thereby validating the process model struc493 ture identified.

494 Methadone. Since formation of EDDP after rapid removal of METD, especially 495 under aerobic conditions, was not observed (Fig. 3), these chemicals were con496 sidered to have independent pathways - similar to that obtained with suspended 497 in-sewer solids. ${ }^{12}$ Our analyses showed rather small deviation between duplicates 498 (sample analysis), i.e. $\leq 7.5 \%$ for METD and $\leq 4.5 \%$ for EDDP.

499 Biotransformation of METD in sewer biofilms was found to be significantly 500 faster under aerobic conditions $\left(k_{\text {biof,ae,METD }}=2488 \quad \mathrm{~L} \mathrm{gTSS}^{-1} \mathrm{~d}^{-1}\right.$, $501 k_{\text {biof,an,METD }}=183 \mathrm{~L} \mathrm{gTSS}^{-1} \mathrm{~d}^{-1}$ ), which agrees well with data obtained with in502 sewer suspended solids. ${ }^{12}$ Conversely, enhanced anaerobic transformation 503 was observed for EDDP $\left(k_{\text {biof,ae,EDDP }}=1.79 \mathrm{~L} \mathrm{gTSS}^{-1} \mathrm{~d}^{-1}, k_{\text {biof,an,EDDP }}=88.9 \mathrm{~L}\right.$ $504 \mathrm{gTSS}^{-1} \mathrm{~d}^{-1}$ ). Simulation results (Fig. 3) for EDDP (both redox conditions) as 505 well as for METD (only anaerobic conditions) indicate a systematic deviation 506 between the predicted and measured values. This may imply that the model 507 structure should be re-evaluated in future studies. A possible explanation 508 could be related to cometabolic effects, i.e. primary substrate oxidation can 509 enhance secondary substrate (i.e. drug biomarker) biotransformation. ${ }^{41-43}$ 510 Additionally, under anaerobic conditions, the sulfate remained constant after 511 day 1 (Figure 2b). This may suggest that readily biodegradable substrates 512 were depleted during the second day of experiment, resulting in negligible 513 removal of EDDP and METD. Nevertheless, simulations could not well pre514 dict the BT-P2 dataset especially for METD, in which lower removal was 515 observed as compared to BT-P1 measurements, as the process model do not 516 account for cometabolic effects.

517 Cocaine. The transformation pathways for COC and its human metabolites 518 were selected based on Bisceglia et al. ${ }^{44}$ Although the biotransformation of 519 COC to EME has been reported to be almost insignificant in raw wastewater 520 and activated sludge ${ }^{16,45}$, in this study EME was considered as a transfor521 mation product (Fig. S6d) of COC in sewer biofilms. Accordingly, it has been 522 reported that, in sewer biofilms, there should be another major transformation 523 product from $\mathrm{COC}$ other than $\mathrm{BE}$ as it was speculated previously. ${ }^{13}$ Net re524 moval of COC, CE and EME and net formation of BE was observed over the 525 duration of experiments, where BE formation resulted from hydrolysis of $526 \mathrm{COC}$ and CE. ${ }^{12,44}$ Under aerobic conditions, the overall biotransformation 527 rate constant of COC, i.e. COC to BE and COC to EME, was lower than un528 der anaerobic conditions $\left(k_{b i o f, a e, C O C}=0.44 \mathrm{~L} \mathrm{gTSS}^{-1} \mathrm{~d}^{-1}, k_{\text {biof, } a n, C O C}=2.57 \mathrm{~L}\right.$ 
529 gTSS$\left.^{-1} \mathrm{~d}^{-1}\right)$. An even more pronounced deviation was observed for EME $530 \quad\left(k_{\text {biof,ae,EME }}=0.05 \mathrm{~L} \mathrm{gTSS}^{-1} \mathrm{~d}^{-1}, k_{\text {biof, } a n, E M E}=21.03 \mathrm{~L} \mathrm{gTSS}^{-1} \mathrm{~d}^{-1}\right)$, mainly due to 531 the high biotransformation of EME in the bulk phase under aerobic condi532 tions, SI Table S3. Aerobic and anaerobic percentage removal of COC only 533 by sewer biofilms was found to be $3 \%$ and $33 \%$ larger than the removal ob534 served in raw wastewater under corresponding redox conditions. ${ }^{12}$ In con535 trast, Thai et al. ${ }^{13}$ found $25 \%$ and $40 \%$ enhancement of COC removal in grav536 ity sewer (aerobic/anaerobic) and rising sewer (anaerobic) conditions, respec537 tively compared to removal with wastewater only. In our study, CE biotrans538 formation kinetics obtained under aerobic and anaerobic biofilms were com539 parable $\left(k_{\text {biof,ae, } C E}=0.68 \mathrm{~L} \mathrm{gTSS}^{-1} \mathrm{~d}^{-1}, k_{\text {biof,an, } C E}=0.51 \mathrm{~L} \mathrm{gTSS}^{-1} \mathrm{~d}^{-1}\right)$. BE is 540 formed from $\mathrm{COC}$ and $\mathrm{CE}$ transformations and also transformed to another 541 unknown transformation product $\left(k_{\text {biof,ae }, B E}=2.00 \mathrm{~L} \mathrm{gTSS}^{-1} \mathrm{~d}^{-1}, k_{b i o f, a n, B E}=0.95\right.$ $\left.542 \mathrm{~L} \mathrm{gTSS}^{-1} \mathrm{~d}^{-1}\right)$. Values of $k_{\text {biof }}^{\prime}\left(\mathrm{m}^{3} \mathrm{~m}^{-2} \mathrm{~d}^{-1}\right)$ estimated in this study (SI, Table $543 \mathrm{~S} 4)$ for overall COC, BE and CE for aerobic biofilms $\left(k^{\prime}{ }_{b i o f, a e, C O C}=0.13 \mathrm{~m}^{3} \mathrm{~m}^{-}\right.$ $5442^{2} \mathrm{~d}^{-1}, k_{\text {biof, } a e, B E}^{\prime}=0.57 \mathrm{~m}^{3} \mathrm{~m}^{-2} \mathrm{~d}^{-1}, k^{\prime}{ }_{\text {biof, } a e, C E}=0.39 \mathrm{~m}^{3} \mathrm{~m}^{-2} \mathrm{~d}^{-1}$ ) are almost 4 times, 54534 and 2 times higher than the values reported by McCall et al. ${ }^{14}$ (aerobic 546 biofilms at $21^{\circ} \mathrm{C}$ ). In contrary, for BE, no transformation by in-sewer sus547 pended solids and sewer biofilms was reported. ${ }^{13}$ The differences are possibly 548 due to different microbes residing in the biofilms in these studies.

549 Heroin. Transformation of heroin biomarkers was assumed to follow the 550 pathways previously described for human metabolism ${ }^{24,35,46}$, namely two-step 551 de-acetylation to 6MAM and to MOR. MORG was also considered to be 552 transformed to MOR via deconjugation. ${ }^{47}$ It was hypothesized that COE was 553 not only transformed to NCOE by sewer biofilms but also to MOR as it was 554 observed in raw wastewater under anaerobic conditions. ${ }^{37}$ Nevertheless, bio555 film-mediated biotransformation processes could be described with transfor556 mation pathways similar to human metabolism. HER was rapidly removed in 557 both sewer biofilms (similarly to raw wastewater (SI, Figure S9), with higher 558 biotransformation kinetics in anaerobic biofilms $\left(k_{\text {biof, } a e, H E R}=4.43 \mathrm{~L} \mathrm{gTSS}^{-1} \mathrm{~d}^{-}\right.$ $559{ }^{1}, k_{\text {biof, an,HER }}=22.14 \mathrm{~L} \mathrm{gTSS}^{-1} \mathrm{~d}^{-1}$ ). Likewise, a five-fold increase of 6MAM 560 biotransformation kinetics was observed in anaerobic biofilms ( $k_{\text {biof,ae, } 6 \text { MAM }}$ $\left.561=1.11 \mathrm{~L} \mathrm{gTSS}^{-1} \mathrm{~d}^{-1}, k_{\text {biof,an, } 6 \text { MAM }}=6.45 \mathrm{~L} \mathrm{gTSS}^{-1} \mathrm{~d}^{-1}\right)$. These differences cannot 562 be explained only by considering differences in the removal of 6MAM in 563 aerobic and anaerobic biofilms (i.e. $33 \%$ and $59 \%$ in aerobic and anaerobic 564 biofilms in $12 \mathrm{~h}$ experimental time (SI, Figure S9). Thus, additional processes 565 are assumed to be involved, notably, the formation of 6MAM from HER. 566 Given that the 6MAM biotransformation by in-sewer suspended solids is sig- 
567 nificantly lower than in biofilms, the total \% removal is not substantially dif568 ferent from those reported by Thai et al. ${ }^{13}$ However, McCall et al. ${ }^{14}$ found 3 569 times higher biotransformation rate for 6MAM by aerobic biofilm compared 570 to in-sewer suspended solids. In this study, as to pathway identification, no 571 additional transformation product of HER was considered when assessing the 572 conservation of HER mass. Moreover, MORG was found to be transformed 573 only by anaerobic sewer biofilm $\left(k_{\text {biof, an,MORG }}=2.03 \mathrm{~L} \mathrm{gTSS}^{-1} \mathrm{~d}^{-1}\right)-$ a rate ap574 proximately 6 times lower than that by in-sewer suspended biomass. ${ }^{12}$ Due to 575 rapid aerobic transformation of MORG in the bulk, no aerobic biofilm576 induced removal was observed for MORG. High transformation of MORG 577 was also observed by Senta et al. ${ }^{8}$ in wastewater.

578 Biotransformation rates obtained for COE and NOE in biofilms are at a mod579 erate level, with NCOE having higher transformation under anaerobic condi580 tions. The simulation model identified can effectively simulate the fate of 581 HER and 6-MAM transformation in the BT-P2 independent datasets, thereby 582 validating the modelling approach.

583 THC. In untreated wastewater, $\mathrm{THCOH}$ was not found to be a transformation 584 product of THC. ${ }^{12}$ Accordingly separate transformation pathways were as585 sumed for THC and THCOH in sewer biofilms. Based on pathways suggested 586 in literature, ${ }^{35} \mathrm{THCCOOH}$ was considered to be formed from $\mathrm{THCOH} .{ }^{35}$ As a 587 result of poor data quality, no clear conclusion could be drawn for THC bio588 transformation especially under anaerobic conditions. Moreover, the $589 k_{b i o f, a e, T H C}=0$ as THC removal was completely attributed to partitioning to the 590 external tank and abiotic hydrolysis. Hence, model calibration could not be 591 performed using THC data set (SI, Figure S10). THCOH exhibited compara592 bly high biotransformation rate constants $\left(k_{\text {biof,ae, } T H C O H}=21034 \mathrm{~L} \mathrm{gTSS}^{-1} \mathrm{~d}^{-1}\right.$, $593 k_{\text {biof, }, \text { an, } \mathrm{THCOH}}=5066 \mathrm{~L} \mathrm{gTSS}^{-1} \mathrm{~d}^{-1}$ ), which were also observed for THCCOOH 594 biotransformation in the anaerobic biofilm $\left(k_{\text {biof, }, \text { an }, \text { ТНССОО }}=3272 \mathrm{~L} \mathrm{gTSS}^{-1} \mathrm{~d}^{-}\right.$ $\left.595^{1}\right)$.

596 We note that the high $k_{\text {biof }}$ values corresponded to high $K_{d f}$ values for these 597 chemicals (SI Table S4), a factor that makes THCOH and THCCOOH less 598 bioavailable for biotransformation. Interestingly, aerobic ТHCCOOH bio599 transformation obtained $\left(k_{\text {biof,ae, } \text { THCCOOH }}=133 \mathrm{~L} \mathrm{gTSS}^{-1} \mathrm{~d}^{-1}\right)$ was lower than 600 that under anaerobic conditions.

601 The impact of mass transfer limitation. Compared to common growth sub602 strates, illicit drug biomarkers are relatively large molecules. The average 603 molar volume, $V_{l}\left(\mathrm{~cm}^{-3} \mathrm{~mol}^{-1}\right)$, of biomarkers in this study is $250 \mathrm{~cm}^{-3} \mathrm{~mol}^{-1}$, 
604 significantly larger than the molar volume of readily biodegradable substrates

605 such as acetate $\left(56.1 \mathrm{~cm}^{-3}\right){ }^{48}$ Therefore, the comparably high molar volume is 606 assumed to significantly impact diffusivity of drug biomarkers in biofilm.

607 In general, the concentration in the boundary layer is proportional to the ratio 608 of convective mass transfer (i.e. axial flow in biofilm reactor) to diffusive 609 mass transport (Sh number). According to eq. 5, molecules with a higher mo610 lar volume and low diffusivity are expected to have lower boundary layers 611 (SI Figure S1). In biofilm modeling studies, typically an average boundary 612 layer is assumed for all chemicals, under the condition that this approxima613 tion does not impact the accuracy of predictions; this, however, is generally 614 done without proper error assessment. Figure 4 (Y-Z axis) illustrates the im615 pact of the choice of boundary layer thickness on the accuracy of estimation 616 of biotransformation rate, $k_{f}$, for the example of MEPH and HER in aerobic 617 biofilms. Estimated values for a range of boundary layer thicknesses (5 to $618100 \mu \mathrm{m}$ ) together with discretization number (10 to 100) were compared with 619 reference predictions for MEPH $(30 \mu \mathrm{m})$ and HER $(20 \mu \mathrm{m})$ with discretiza620 tion number of 100 . These results indicate that the impact of the boundary 621 layer thickness on parameter estimates (i) is compound-specific; and (ii) var622 ies by the discretization number employed (Figure $4 \mathrm{X}-\mathrm{Z}$ axis). A higher in623 fluence was observed for more reactive compounds, i.e. HER, at lower dis624 cretization numbers. In Figure 4, red dots denote the values employed in this 625 study (discretization number=80 layers; boundary layer thickness $=23 \mu \mathrm{m}$ ). 626 Furthermore, diffusion of HER and MEPH was compared in aerobic and an627 aerobic biofilms through simulation of diffusive transport, considering negli628 gible partitioning to solids and transformation (SI Figure S12). Following the 629 spiking of internal standards in BT-P1 experiments, the concentrations in the 630 bulk phase of the reactors were predicted to reach an equilibrium level after 2 $631 \mathrm{~h}$ in aerobic biofilms and $4 \mathrm{~h}$ in anaerobic biofilms. These delays show the 632 impact of mass transfer limitation across the boundaries of biofilm and liquid 633 phase - a factor that necessitates an effective diffusion modelling for which 634 we provided an example here. Moreover, the recirculation between external 635 tank and reactor cause additional limiting step for reaching equilibrium. An 636 example of concentration profile inside the biofilm is also presented for 637 MEPH (SI, Figure S13).

638 Transformation in raw wastewater and sewer biofilms - A comparison. 639 Biotransformation rate constants in sewer biofilms $k_{\text {biof }}$ estimated in this 640 study were compared rate constants in the presence of suspended solids, $k_{\text {bio }}$ 641 (Figure 5). ${ }^{12}$ Under aerobic conditions (reproducing a gravity sewer), most 
642 biomarkers exhibited similar $k_{b i o f}$ and $k_{b i o}$ values (see error bars in Figure 5).

643 Biofilm-mediated transformations were found to be dominant for COE and 644 NCOE, whilst the majority of MORG and MOR transformation occurred in 645 the bulk water by suspended biomass. Under anaerobic conditions, MEPH, 646 METD, COC, EME, CE, THCOH, and THCCOOH were found to be bio647 transformed only in biofilms. Moreover, no additional major transformation 648 products for HER and MORG, other than 6MAM and MOR, respectively, 649 were identified in the biofilm reactors, as opposed to raw wastewater.

650 Future perspectives. In this study, we assessed the transformation of 16 drug 651 biomarkers in biofilm reactors under aerobic and anaerobic conditions, repre652 senting typical conditions in gravity and pressure sewers (respectively). This 653 investigation complemented our previous study ${ }^{12}$ on the fate of drug bi654 omarkers in raw sewage, in the presence of suspended biomass only. A com655 parative assessment of the results indicates that sewer biofilms enhance the 656 transformation kinetics of many of selected drug biomarkers, particularly un657 der anaerobic conditions (Figure 5), likely due to higher anaerobic activity in 658 biofilms than in suspended biomass. Under aerobic conditions, transfor659 mation kinetics in biofilms was overall comparable to that observed for un660 treated sewage, indicating again limited stability of selected biomarkers. This 661 evidence suggests the necessity of accounting for biofilm-mediated transfor662 mation when predicting in-sewer fate of drug biomarkers. Moreover, for the 663 reliable prediction of trace organic chemical fate in biofilm, the mathematical 664 consistency of simulation model structures should be assessed.

665 More observations are needed to validate sorption and transformation of THC 666 in sewer biofilms. In this study all drug biomarkers (parents and metabolites) 667 were spiked simultaneously to simulate environmentally-relevant conditions, 668 i.e. the occurrence of drug biomarkers in sewer as a mixture. The model de669 veloped can accurately predict the transformation of biomarkers. Neverthe670 less, future experimental designs could benefit from spiking unrelated bi671 omarkers (e.g., in separate batch experiments) or using biomarkers with sev672 eral different labels, although resulting in a drastic increase of the cost of 673 chemical analysis.

674 The microbial activity of the two biofilms in this study was characterized by 675 monitoring utilization of primary substrates (e.g., organic carbon, sulfate) 676 during batch experiments. Our results showed substantial differences in mi677 crobial activity between the two biofilms assessed in this study, e.g., signifi678 cantly higher sulfate-reducing activity in the anaerobic biofilm. In sewer sys- 
679 tems, microbial functions and community of sewer biofilms likely vary over a

680 sewer length, as a result of changes in boundary conditions and gradients in 681 substrate concentrations and wastewater composition. To date, this has been 682 demonstrated for gravity sewers ${ }^{14}$. Hence, further research is required to 683 characterize microbial activity of the sewer biofilms at different sewer loca684 tions and correlate the microbial community and activity with biotransfor685 mation rates.

686 In this study, the aeration was performed in a separate tank and not directly in 687 the biofilm reactor. The objective was to provide sufficient oxygen supply to 688 ensure that most microorganisms would be exposed to aerobic conditions. It 689 should be noted that (re)aeration may be different in full-scale sewer systems, 690 being caused by flow fluctuations and mixing. The current study potentially 691 offers the background for a combined modelling framework for real sewers, 692 where switching functions based on dissolved oxygen concentration would 693 allow differentiating between aerobic and anaerobic conditions.

694 Although this study compared the biotransformation rate in raw wastewater 695 and in biofilms, the contribution of each of these biotransformation processes 696 to the overall drug biomarkers removal should be assessed. Moreover, the 697 assessment of drug abuse rates at catchment level should account for, im698 portantly, the layout of the sewer system, hydraulic conditions ${ }^{49}$ and drug re699 lease patterns. Additionally, model-based back-calculation tools should ac700 count for abiotic processes and biotransformation induced by suspended bio701 mass and sewer biofilms. ${ }^{50}$ Hence, a reactive-transport model needs to be de702 veloped, describing drug biomarkers transformation under steady state and 703 dynamic hydraulic conditions. Transformation rates estimated in this study 704 can be used in such a model for back-calculation purposes. Our ongoing re705 search $^{50}$ is addressing the impact of neglecting in-sewer biotransformation on 706 estimation of daily drug consumption in catchments using uncertainty analy707 sis and measurements from sampling campaigns. Results presented in this 708 study underscore the high level of complexity of in-sewer biomarker fate, of 709 which the implications to wastewater-based epidemiological engineering are 710 numerous.

\section{Acknowledgments}

712 This study was supported by the European Union's Seventh Framework Pro713 gramme for research, technological development and demonstration [grant 714 agreement 317205, the SEWPROF MC ITN project]. Borja Valverde-Pérez 
715 thanks the Technical University of Denmark (DTU) for the financial support 716 through the KAIST-DTU project on Integrated Water Technology (In717 WaTech, http://www.inwatech.org). 


\section{Reference}

719 (1) Thomas, K. V.; Bijlsma, L.; Castiglioni, S.; Covaci, A.; Emke, E.; Grabic, R.;

(3) Hvitved-Jacobsen, T.; Vollertsen, J.; Matos, J. S. The sewer as a bioreactor - A dry weather approach. Water Sci. Technol. 2002, 45 (3), 11-24.

730

(4) Jelic, A.; Rodriguez-Mozaz, S.; Barceló, D.; Gutierrez, O. Impact of in-sewer transformation on 43 pharmaceuticals in a pressurized sewer under anaerobic conditions. Water Res. 2014, 68, 98-108.

McCall, A.-K.; Bade, R.; Kinyua, J.; Lai, F. Y.; Thai, P. K.; Covaci, A.; Bijlsma, L.; van Nuijs, A. L. N.; Ort, C. Critical review on the stability of illicit drugs in sewers and wastewater samples. Water Res. 2016, 88, 933-947.

(6) Castiglioni, S.; Bijlsma, L.; Covaci, A.; Emke, E.; Hernández, F.; Reid, M.; Ort, C.; Thomas, K. V.; Van Nuijs, A. L. N.; De Voogt, P.; et al. Evaluation of uncertainties associated with the determination of community drug use through the measurement of sewage drug biomarkers. Environ. Sci. Technol. 2013, 47 (3), 1452-1460.

van Nuijs, A. L. N.; Abdellati, K.; Bervoets, L.; Blust, R.; Jorens, P. G.; Neels, H.; Covaci, A. The stability of illicit drugs and metabolites in wastewater, an important issue for sewage epidemiology? J. Hazard. Mater. 2012, 239-240, 19-23.

(8) Senta, I.; Krizman, I.; Ahel, M.; Terzic, S. Assessment of stability of drug biomarkers in municipal wastewater as a factor influencing the estimation of drug consumption using sewage epidemiology. Sci. Total Environ. 2014, 487, 659-665.

746

Baker, D. R.; Očenášková, V.; Kvicalova, M.; Kasprzyk-Hordern, B. Drugs of abuse in wastewater and suspended particulate matter - Further developments in sewage epidemiology. Environ. Int. 2012, 48, 28-38.

(10) Baker, D. R.; Kasprzyk-Hordern, B. Critical evaluation of methodology commonly used in sample collection, storage and preparation for the analysis of pharmaceuticals and illicit drugs in surface water and wastewater by solid phase extraction and liquid chromatography-mass spectrometry. J. Chromatogr. A 2011, 1218 (44), 8036-8059.

(11) Polesel, F.; Andersen, H. R.; Trapp, S.; Plósz, B. G. Removal of Antibiotics in Biological Wastewater Treatment Systems $\square$ A Critical Assessment Using the Activated Sludge Modeling Framework for Xenobiotics (ASM-X). Environ. Sci. Technol. 2016, 50 (19), 10316-10334.

(12) Ramin, P.; Brock, A. L.; Polesel, F.; Causanilles, A.; Emke, E.; de Voogt, P.; Plósz, B. G. Transformation and sorption of illicit drug biomarkers in sewer systems: understanding the role of suspended solids in raw wastewater. Environ. Sci. Technol. 2016, 50 (24), 13397-13408. 
762

763

764

765

766

767

768

769

770

771

772

773

774

775

776

777

778

779

780

781

782

783

784

785

786

787

788

789

790

791

792

793

794

795

796

797

798

799

800

801

802

803

804

(13) Thai, P. K.; Jiang, G.; Gernjak, W.; Yuan, Z.; Lai, F. Y.; Mueller, J. F. Effects of sewer conditions on the degradation of selected illicit drug residues in wastewater. Water Res. 2014, 48, 538-547.

(14) McCall, A.-K.; Scheidegger, A.; Madry, M. M.; Steuer, A. E.; Weissbrodt, D. G.; Vanrolleghem, P. A.; Kraemer, T.; Morgenroth, E.; Ort, C. Influence of different sewer biofilms on transformation rates of drugs. Environ. Sci. Technol. 2016, 50 (24), 13351-13360.

(15) Ort, C.; Gujer, W. Sorption and high dynamics of micropollutants in sewers. Water Sci. Technol. 2008, 57 (11), 1791-1797.

(16) Plósz, B. G.; Reid, M. J.; Borup, M.; Langford, K. H.; Thomas, K. V. Biotransformation kinetics and sorption of cocaine and its metabolites and the factors influencing their estimation in wastewater. Water Res. 2013, 47 (7), 21292140 .

(17) Bisceglia, K. J.; Lippa, K. a. Stability of cocaine and its metabolites in municipal wastewater - the case for using metabolite consolidation to monitor cocaine utilization. Environ. Sci. Pollut. Res. 2014, 21 (516), 4453-4460.

(18) Jiang, F.; Leung, D. H.-W. W.; Li, S.; Chen, G.-H. H.; Okabe, S.; van Loosdrecht, M. C. M. A biofilm model for prediction of pollutant transformation in sewers. Water Res. 2009, 43 (13), 3187-3198.

(19) Schwarzenbach, R. P.; Gschwend, P. M.; Imboden, D. M. Environmental Organic Chemistry; Wiley Interscience: Hoboken, NJ, 2003.

(20) Wicke, D.; Böckelmann, U.; Reemtsma, T. Experimental and modeling approach to study sorption of dissolved hydrophobic organic contaminants to microbial biofilms. Water Res. 2007, 41 (10), 2202-2210.

(21) Torresi, E.; Polesel, F.; Bester, K.; Christensson, M.; Smets, B. F.; Trapp, S.; Andersen, H. R.; Plósz, B. G. Diffusion and sorption of organic micropollutants in biofilms with varying thicknesses. Water Res. 2017.

(22) Huisman, J. L.; Gujer, W. Modelling wastewater transformation in sewers based on ASM3. Water Sci. Technol. 2002, 45 (6), 51-60.

(23) EMCDDA. European Drug Report; 2017.

(24) Boerner, U.; Abbott, S.; Roe, R. L. The Metabolism of Morphine and Heroin in Man. Drug Metab. Rev. 1975, 4 (1), 39-73.

(25) Rochex, A.; Godon, J.; Bernet, N.; Escudie, R. Role of shear stress on composition, diversity and dynamics of biofilm bacterial communities. Water Res. 2008, 42, 4915-4922.

(26) Oms, C.; Gromaire, M. C.; Saad, M.; Milisic, V.; Chebbo, G.; Gromaire, M. C.; Saad, M.; Milisic, V.; Bed, G. C. Bed shear stress evaluation in combined sewers. Urban Water J. 2008, 5 (3), 219-229.

(27) APHA. Standard methods for the examination of water and wastewater. American Public Health Association, 19th ed.; Washington, D.C, 1995.

(28) Bijlsma, L.; Emke, E.; Hernández, F.; de Voogt, P. Performance of the linear ion trap Orbitrap mass analyzer for qualitative and quantitative analysis of drugs of abuse and relevant metabolites in sewage water. Anal. Chim. Acta 2013, 768 (1), 
$102-110$.

806

807

808

809

810

811

812

813

814

815

816

817

818

819

820

821

822

823

824

825

826

827

828

829

830

831

832

833

834

835

836

837

838

839

840

841

842

843

844

845

846

847

(29) Horn, H.; Hempel, D. C. Modeling mass transfer and substrate utilization in the boundary layer of biofilm systems. Water Sci. Technol. 1998, 37 (4-5), 139-147.

(30) Othmer, D. F.; Thakar, M. S. Correlating Diffusion Coefficients in Liquids. Ind. Eng. Chem. 1953, 45 (3), 589-593.

(31) Hayduk, W.; Laudie, H. Prediction of diffusion coefficients for nonelectrolytes in dilute aqueous solutions. AIChE J. 1974, 20 (3), 611-615.

(32) Guimerà, X.; Dorado, A. D.; Bonsfills, A.; Gabriel, G.; Gabriel, D.; Gamisans, X. Dynamic characterization of external and internal mass transport in heterotrophic biofilms from microsensors measurements. Water Res. 2016, 102, 551-560.

(33) Wanner, O.; Eberl, H. J.; Morgenroth, E.; Noguera, D. R.; Picioreanu, C.; Rittmann, B. E.; van Loosdrecht, M. C. . Mathematical modeling of biofilms; 2006.

(34) Recktenwald, A.; Lücke, M.; Müller, H. W. Taylor vortex formation in axial through-flow: Linear and weakly nonlinear analysis. Phys. Rev. E 1993, 48 (6), 4444-4454.

(35) Castiglioni, S.; Zuccato, E.; Fanelli, R. Illicit Drugs in the Environment: Occurrence, Analysis, and Fate Using Mass Spectrometry; JohnWiley \& Sons, Inc, 2011.

(36) Laloy, E.; Vrugt, J. a. High-dimensional posterior exploration of hydrologic models using multiple-try DREAM(ZS) and high-performance computing. Water Resour. Res. 2012, 48 (1), 1-18.

(37) Ramin, P.; Valverde-Pérez, B.; Polesel, F.; Locatelli, L.; Plósz, B. G. A systematic model identification method for chemical transformation pathways - the case of heroin biomarkers in wastewater. Sci. Report, Accept. with Revis. 2017.

(38) Vangsgaard, A. K.; Mauricio-Iglesias, M.; Gernaey, K. V.; Smets, B. F.; Sin, G. Sensitivity analysis of autotrophic $\mathrm{N}$ removal by a granule based bioreactor: Influence of mass transfer versus microbial kinetics. Bioresour. Technol. 2012, 123, $230-241$.

(39) Sin, G.; Gernaey, K. V.; Neumann, M. B.; van Loosdrecht, M. C. M.; Gujer, W. Uncertainty analysis in WWTP model applications: A critical discussion using an example from design. Water Res. 2009, 43 (11), 2894-2906.

(40) Rosa Boleda, M.; Huerta-Fontela, M.; Ventura, F.; Galceran, M. T. Evaluation of the presence of drugs of abuse in tap waters. Chemosphere 2011, 84 (11), 16011607.

(41) Plósz, B. G.; Langford, K. H.; Thomas, K. V. An activated sludge modeling framework for xenobiotic trace chemicals (ASM-X): Assessment of diclofenac and carbamazepine. Biotechnol. Bioeng. 2012, 109 (11), 2757-2769.

(42) Torresi, E.; Fowler, J. S.; Polesel, F.; Bester, K.; Andersen, H. R.; Smets, B. F.; Plósz, B. G.; Christensson, M. Biofilm thickness influences biodiversity in nitrifying MBBRs - Implications on micropollutant removal. Environ. Sci. Technol. 2016, 50 (17), 9279-9288.

(43) Sathyamoorthy, S.; Chandran, K.; Ramsburg, C. A. Biodegradation and Cometabolic Modeling of Selected Beta Blockers during Ammonia Oxidation. 
Environ. Sci. Technol. 2013, 47, 12835-12843.

849

850

851

852

853

854

855

856

857

858

859

860

861

862

863

864

865

866

867

868

869
(44) Bisceglia, K. J.; Roberts, A. L.; Lippa, K. A. A hydrolysis procedure for the analysis of total cocaine residues in wastewater. Anal. Bioanal. Chem. 2012, 402, $1277-1287$.

(45) Bisceglia, K. J. K.; Lippa, K. a. Stability of cocaine and its metabolites in municipal wastewater - the case for using metabolite consolidation to monitor cocaine utilization. Environ. Sci. Pollut. Res. 2014, 21 (6), 4453-4460.

(46) Stefanidou, M.; Athanaselis, S.; Spiliopoulou, C.; Dona, A.; Maravelias, C. Biomarkers of opiate use. Int. J. Clin. Pract. 2010, 64 (12), 1712-1718.

(47) Castiglioni, S.; Zuccato, E.; Crisci, E.; Chiabrando, C.; Fanelli, R.; Bagnati, R. Identification and measurement of illicit drugs and their metabolites in urban wastewater by liquid chromatography-tandem mass spectrometry. Anal. Chem. 2006, 78 (24), 8421-8429.

(48) ACD/I-Lab 2.0 Prediction Software by Advanced Chemistry Development Inc. $(\mathrm{ACD} / \mathrm{Labs})$.

(49) Mccall, A.; Palmitessa, R.; Blumensaat, F.; Morgenroth, E.; Ort, C. Modeling insewer transformations at catchment scale - Implications on drug consumption estimates in wastewater-based epidemiology. Water Res. 2017.

(50) Ramin, P. Modelling Illicit Drug Fate in Sewers for Wastewater-Based Epidemiology, PhD Thesis, Technical University of Denmark, 2016. 
870 Table 1. Model state variables and parameters

\begin{tabular}{|c|c|c|c|}
\hline Symbol & Definition & Units & Values \\
\hline$A_{b}$ & Biofilm area & $\mathrm{m}^{2}$ & $4.10^{-3}$ \\
\hline$C_{R}$ & Concentration of drug biomarkers in reactor & $\mathrm{g} \mathrm{L}^{-1}$ & \\
\hline$C_{b}$ & Concentration of drug biomarkers inside biofilm & $\mathrm{g} \mathrm{L}^{-1}$ & \\
\hline$C_{T}$ & Concentration of drug biomarkers in external tank bulk phase & $\mathrm{g} \mathrm{L}^{-1}$ & \\
\hline$C_{T w}$ & Concentration of drug biomarkers sorbed onto external tank wall & $\mathrm{g} \mathrm{L}^{-1}$ & \\
\hline$d$ & Gap between rotating drum and stationary cylinder $\left(R_{2}-R_{l}\right)$ & $\mathrm{m}$ & 0.012 \\
\hline$d_{R}$ & Reactor Characteristic length $(2 d)$ & $\mathrm{m}$ & 0.024 \\
\hline$D$ & Diffusion coefficient of the soluble compounds into the biofilm & $m^{2} d^{-1}$ & Table S2 \\
\hline$D_{w}$ & Diffusion coefficient of the soluble compounds in water & $\mathrm{m}^{2} \mathrm{~d}^{-1}$ & Table S2 \\
\hline$f$ & Dimensionless effective diffusivity & - & ${ }^{(\mathrm{a})} 0.68 ;{ }^{(\mathrm{b})} 0.38$ \\
\hline$\overline{j_{b}}$ & Flux of compounds between bulk phase and the biofilm & $\mathrm{g} \mathrm{m}^{-2} \mathrm{~d}^{-1}$ & \\
\hline$k_{b}$ & Mass transfer coefficient between bulk phase and the biofilm & $\mathrm{m} \mathrm{d}^{-1}$ & \\
\hline$k_{d e s, w}$ & Desorption from reactor wall & $\mathrm{d}^{-1}$ & 100 \\
\hline$K_{d w}$ & Reactor wall-liquid partition coefficient & $\mathrm{m}^{3} \mathrm{~m}^{-2}$ & Ramin et al. ${ }^{12}$ \\
\hline$K_{d}$ & Suspended Solid-liquid partition coefficient & $\mathrm{L} \mathrm{gTSS}^{-1}$ & Ramin et al. $^{12}$ \\
\hline$K_{d f}$ & Suspended biofilm-liquid partition coefficient & $\mathrm{L} \mathrm{gTSS}^{-1}$ & Table S4 \\
\hline$k_{\text {abio }}$ & Abiotic transformation rate constant & $\mathrm{d}^{-1}$ & Ramin et al. $^{12}$ \\
\hline$k_{\text {bio }}$ & TSS-normalized biotransformation rate constant & $\mathrm{LgTSS}^{-1} \mathrm{~d}^{-1}$ & Ramin et al. ${ }^{12}$ \\
\hline$k_{f}$ & Sewer biofilm biotransformation rate (eq. 9) & $\mathrm{d}^{-1}$ & Figure S11 \\
\hline$k_{\text {biof }}$ & TSS-normalized Sewer biofilm biotransformation rate & $\mathrm{LgTSS}^{-1} \mathrm{~d}^{-1}$ & Table S4 \\
\hline$k_{\text {biof }}^{\prime}$ & Area-to-volume-normalized Sewer biofilm biotransformation rate & $\mathrm{m}^{3} \mathrm{~m}^{-2} \mathrm{~d}^{-1}$ & Table S4 \\
\hline$L_{b}$ & Concentration boundary layer & $\mathrm{m}$ & $2310^{-6}$ \\
\hline$M$ & Biomarker molecular weight & $\mathrm{g} \mathrm{mol}^{-1}$ & Table S2 \\
\hline$O$ & Observed (measured) values & & \\
\hline$P$ & Predicted (simulated) values & & \\
\hline$Q_{i n, R}$ & Reactor inflow & $\mathrm{m}^{3} \mathrm{~d}^{-1}$ & (c) $410^{-3} ;^{\text {(d) }} 9.610^{-2}$ \\
\hline$Q_{\text {out }, R}$ & Reactor outflow & $\mathrm{m}^{3} \mathrm{~d}^{-1}$ & (c) $410^{-3} ;^{\text {(d) }} 9.610^{-2}$ \\
\hline$Q_{i n, T}$ & External tank inflow & $\mathrm{m}^{3} \mathrm{~d}^{-1}$ & ${ }^{(\mathrm{c})} 410^{-3} ;^{(\mathrm{d})} 9.610^{-2}$ \\
\hline$Q_{\text {out }, T}$ & External tank outflow & $\mathrm{m}^{3} \mathrm{~d}^{-1}$ & (c) $410^{-3} ;^{(\mathrm{d})} 9.610^{-2}$ \\
\hline$r_{R}$ & Reaction rate in reactor & $\mathrm{g} \mathrm{L} \mathrm{d}^{-1}$ & \\
\hline$r_{b}$ & Reaction rate in side biofilm & $\mathrm{g} \mathrm{L} \mathrm{d}^{-1}$ & \\
\hline$r_{T}$ & Reaction rate in external tank & $\mathrm{g} \mathrm{L} \mathrm{d}^{-1}$ & \\
\hline$R_{l}$ & Reactor inner radios (outer radios of rotating drum) & $\mathrm{m}$ & 0.045 \\
\hline$R_{2}$ & Reactor outer radios (inner radios of stationary cylinder) & $\mathrm{m}$ & 0.057 \\
\hline$V_{R}$ & Total reactor volume & $\mathrm{m}^{3}$ & $9.6110^{-4}$ \\
\hline $\bar{u}$ & Average axial velocity inside reactor & $\mathrm{m} \mathrm{s}^{-1}$ & ${ }^{(\mathrm{c})} 0.1210^{-4} ;^{\text {(d) }} 2.8910^{-4}$ \\
\hline$V_{b}$ & Biofilm volume & $\mathrm{m}^{3}$ & (a) $1.2510^{-4} ;^{(\mathrm{b})} 1.7110^{-4}$ \\
\hline$V_{T}$ & Bulk volume in external volume & $\mathrm{m}^{3}$ & Figure S2 \\
\hline$V_{1}$ & Molar volume & $\mathrm{cm}^{3} \mathrm{~g} \mathrm{~mole}^{-1}$ & Table S2 \\
\hline$X_{S S}$ & Concentration of suspended solids & gTSS L & Table S3 \\
\hline$\Delta Z$ & $\begin{array}{l}\text { Discretization distance inside biofilm for spatial discretization of } \\
\text { partial differential equations }\end{array}$ & $\mathrm{m}$ & (a) $9.310^{-6} ;^{(b)} 12.810^{-6}$ \\
\hline$\mu_{w}$ & Dynamic viscosity of water $\left(\right.$ at $\left.\sim 17^{\circ} \mathrm{C}\right)$ & $\mathrm{kg} \mathrm{m}^{-1} \mathrm{~s}^{-1}$ & $1.0710^{-3}$ \\
\hline$v$ & Kinematic viscosity of water $\left(\right.$ at $\left.\sim 17^{\circ} \mathrm{C}\right)$ & $\mathrm{m}^{-2} \mathrm{~s}^{-1}$ & $1.0710^{-6}$ \\
\hline$\sigma_{w}$ & Wet-surface-to-volume ratio & $\mathrm{m}^{2} \mathrm{~m}^{-3}$ & Figure S2 \\
\hline$\Omega$ & Angular velocity of rotating drum & $\operatorname{rad~d}^{-1}$ & 2.09 \\
\hline
\end{tabular}




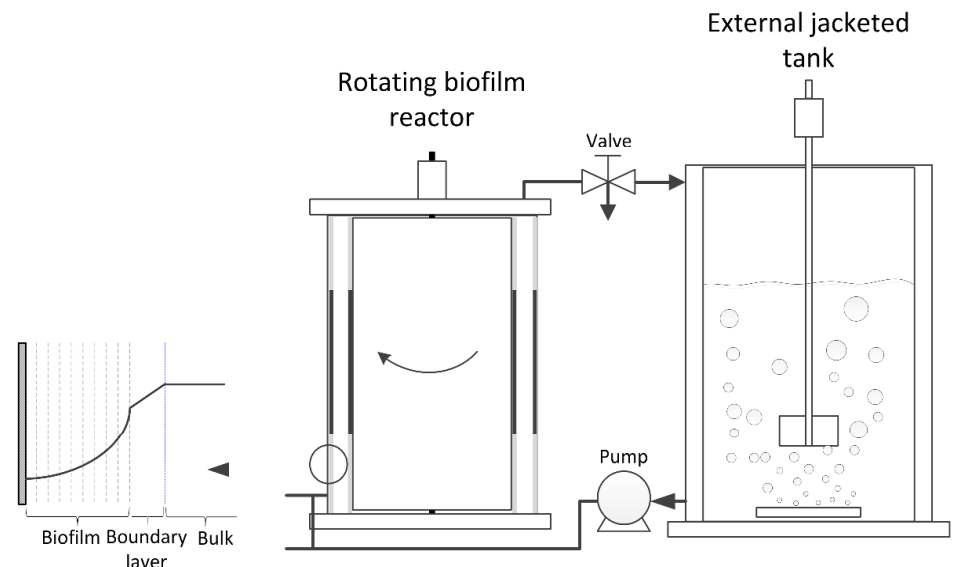

874 Figure 1. Configuration of rotating biofilm reactor (on the left) connected to an external tank 875 (on the right) during batch experiments. The samples were taken from the outlet of the biofilm 876 reactor, on the top valve. Anaerobic or aerobic conditions were maintained in the external tank 877 by sparging dried air or nitrogen, respectively, from a diffuser placed at the bottom of the tank. 878 A typical drug concentration profile inside the biofilm is also presented.

879

880

(a)

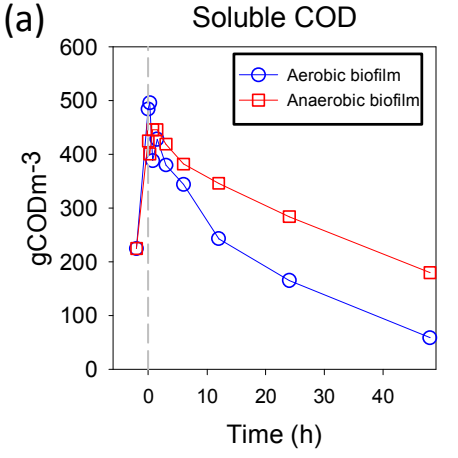

(b)

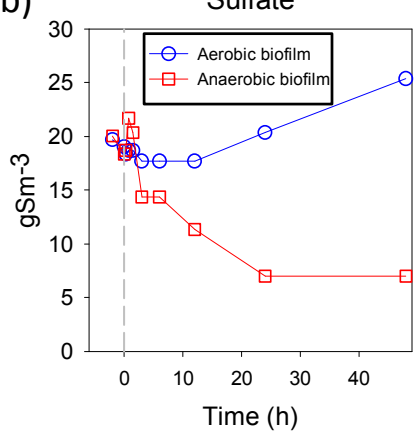

(c)

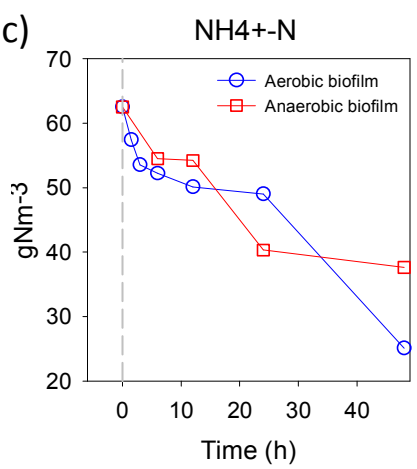

881 Figure 2. Soluble COD, sulfate and ammonium concentrations measured during BT-P1 882 experiments under aerobic and anaerobic conditions. Measurements before $t=0$ refer to 883 samples taken prior to the spiking of standards, and the subsequent increase of soluble 884 COD concentration at $\mathrm{t}=0$ should be associated with the addition of $\mathrm{MeOH}$ resulting from 885 spiking of biomarkers mixture. Lines connecting data points are based on simple linear 886 interpolation to show the trends. 

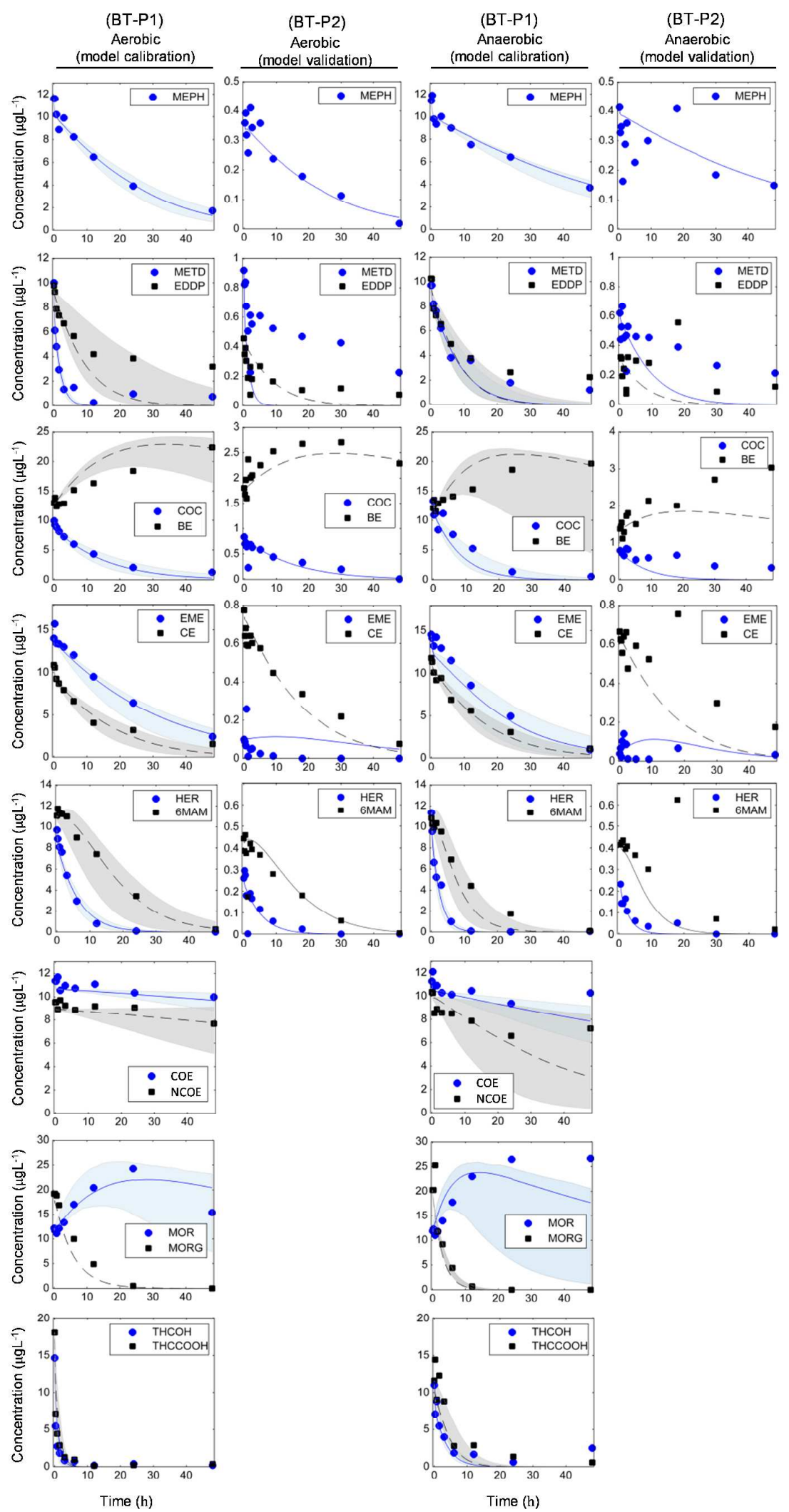
889 Figure 3. Experimental data and simulation results for biomarker transformations in sewer 890 biofilm under aerobic and anaerobic conditions. Results are related to model calibration 891 using BT-P1 experimental data and model validation using BT-P2 experimental data. THC 892 data is presented in (SI, Figure S10). Markers are measured data and lines are simulation 893 results. The shaded areas reflect $95 \%$ credibility interval of model prediction. 

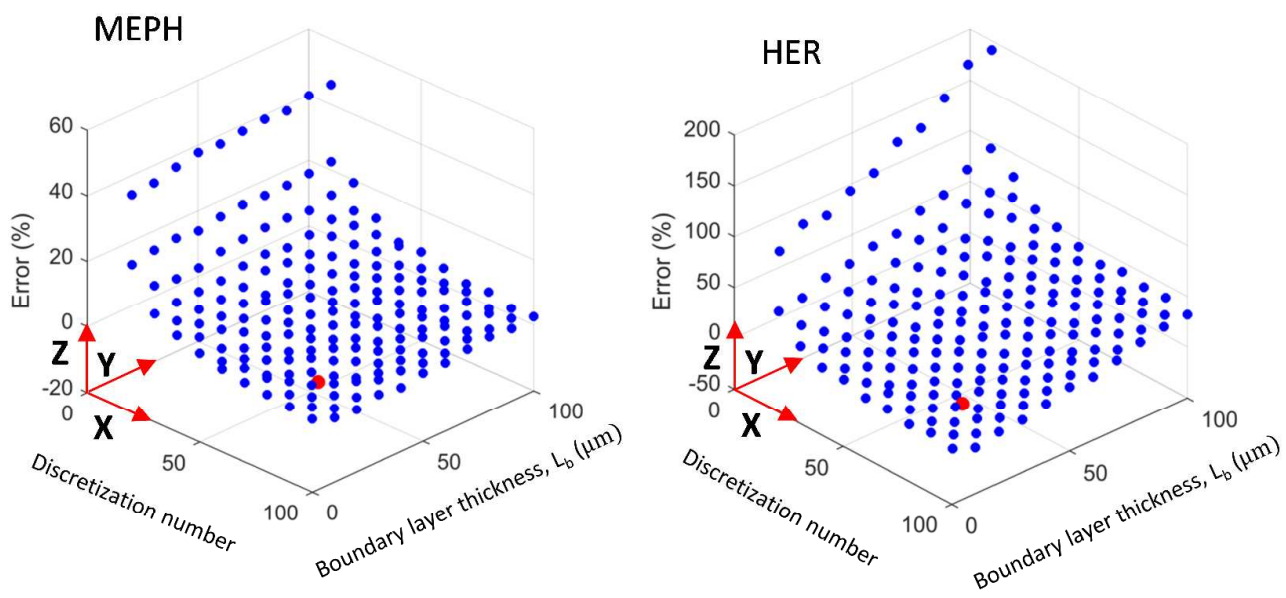

895 Figure 4. The impact of discretization number (number of discretization layers considered 896 for numerical integration in biofilm) and boundary layer thickness on estimation of aerobic 897 transformation rate, $k_{f}\left(\mathrm{~d}^{-1}\right)$, for MEPH and HER. 190 scenarios were considered for each 898 chemical. The parameter estimate at each scenario was compared with the reference sce899 nario for each chemical. The reference scenario contained 100 layers using the accurate 900 estimation of boundary layer thickness, i.e. $30 \mu \mathrm{m}$ for MEPH and $20 \mu \mathrm{m}$ for HER. Blue 901 dots are the data resulted from scenarios and red dots correspond to the values chosen in 902 this study (i.e. 80 discretization number and $23 \mu \mathrm{m}$ boundary layer thickness). Considering 903 this choice resulted in an acceptable error i.e. 0.4\% for MEPH and 2\% for HER. 


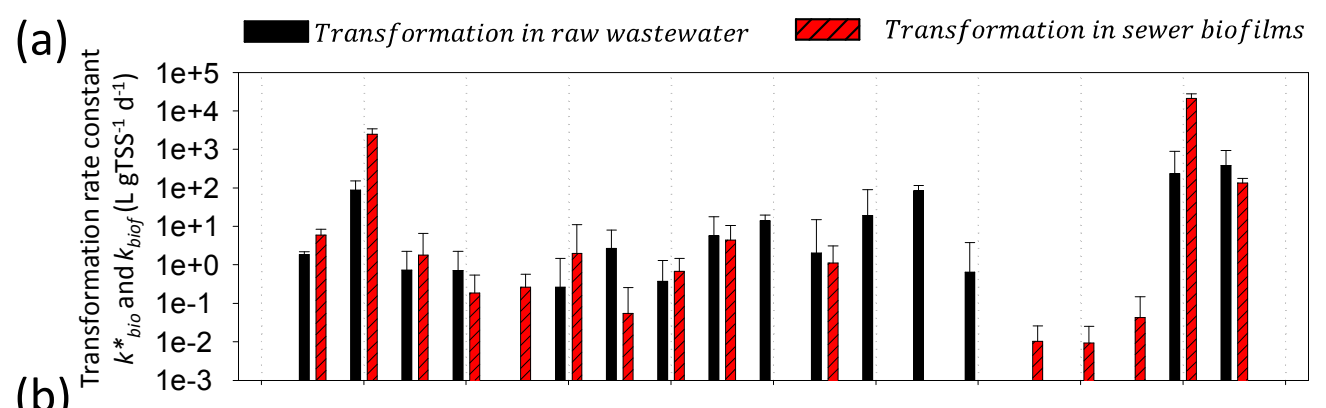

(b)

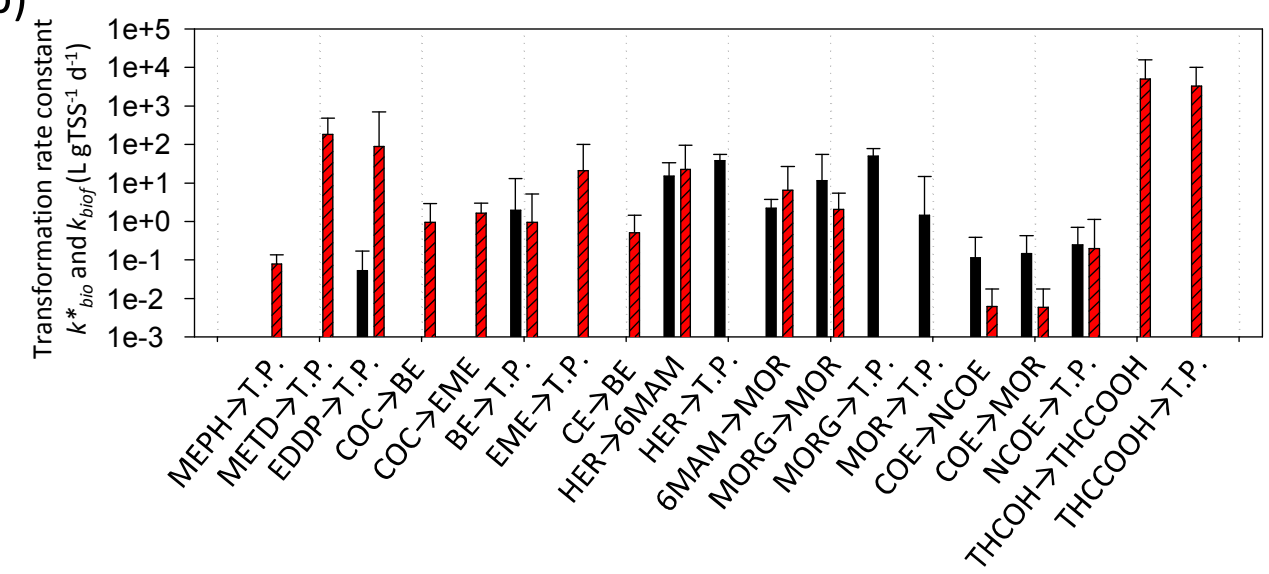

905

906 Figure 5. Comparing the biotransformation of drug biomarkers in raw wastewater and 907 biotransformation in sewer biofilms under aerobic (a), and anaerobic (b) conditions. For 908 this comparison, TSS-normalized transformation rate constants in raw wastewater $k_{b i o}$ (L $\left.909 \mathrm{gTSS}^{-1} \mathrm{~d}^{-1}\right)$ reported in Ramin et al. ${ }^{12}$ are compared with sewer biofilm-mediated transfor910 mation rate constants, $k_{\text {biof }}\left(\mathrm{L} \mathrm{gTSS}^{-1} \mathrm{~d}^{-1}\right)$, from this study. Error bars identify the upper 911 bound of the $95 \%$ credibility interval of estimated parameters. 


\section{TOC/graphical abstract}

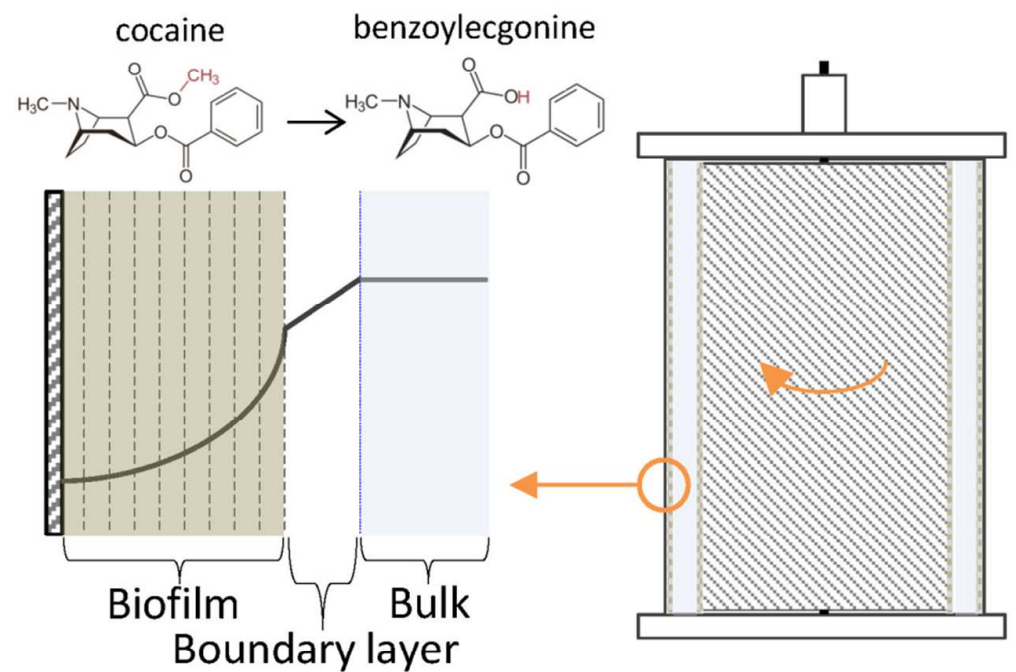

913 